\title{
An Appraisal of the Global Warming: Problems Issues Corrective Measures
}

\author{
B D Pandey
}

\begin{abstract}
Increasing concentration of green house gases produced by human activities is considered as the principal cause of global warming. Carbon dioxide $\left(\mathrm{CO}_{2}\right)$ emissions occur from fossil fuel combustion, cement production, and the use of land for agriculture resulting in deforestation. Human influence is also related to warming of the atmosphere and the ocean, changes in the global water cycle, reductions in snow and ice, global mean sea level rise, and changes in some climate extremes. In this particular feature article; potential impacts and issues related to global warming have been addressed, strategies for mitigation as well as adaptation to climate change described and corrective measures being adopted worldwide for solving the global warming related problems outlined.
\end{abstract}

Keywords--- Environment Pollution, Photosynthesis, Forests Conservation, Renewable Energy Sources

\section{INTRODUCTION}

$\mathrm{C}$ LIMATE change and global warming is a significant variation in weather patterns with time occurring over periods ranging from decades to millions of years. It may refer to a change in average weather conditions (i.e. more or fewer extreme weather events) or variation of weather with time around longer-term average conditions. It is caused by factors such as biotic processes, variations in solar radiation received by earth, plate tectonics, and volcanic eruptions. Certain human activities have also been identified as significant causes of recent climate change, often referred to as "global warming".

Climate change and global warming is considered as the single biggest environmental and humanitarian crisis of the present time. The Earth's atmosphere is overloaded with heattrapping carbon dioxide, which threatens large-scale disruptions in climate with disastrous consequences. The whole world is being compelled to act now to spur the adoption of cleaner energy sources at home and abroad. It is primarily a problem of too much carbon dioxide $\left(\mathrm{CO}_{2}\right)$ in the atmosphere which acts as a blanket, trapping heat and warming the planet. As we burn fossil fuels like coal, oil and natural gas for energy or cut down and burn forests to create

Disclaimer: The present article is not based on author's original research findings. It is the collection and compilation of facts and figures from the published literatures (Internet Search/Websites).

$B D$ Pandey, Ex Researcher, $R \& D$ Tata Steel, Jamshedpur, India. E-mail:bdpandey_1@yahoo.com

DOI: 10.9756/BIJIEMS.10405 pastures and plantations, carbon accumulates and overloads our atmosphere. Certain waste management and agricultural practices aggravate the problem by releasing other potent global warming gases, such as methane and nitrous oxide. Environmental pollutions with regard to air, water. Soil, noise etc., further aggravate the problems.

Increasing concentration of greenhouse gases produced by human activities is the principal cause of global warming. Carbon dioxide $\left(\mathrm{CO}_{2}\right)$ emissions occur from fossil fuel combustion, cement production, and the use of land for agriculture resulting in deforestation. Human influence is also related to warming of the atmosphere and the ocean, changes in the global water cycle, reductions in snow and ice, global mean sea level rise, and changes in some climate extremes.

\section{POTENTIAL EFFECTS AND ISSUES ${ }^{[1-20]}$}

Abrupt climate change: In the context of global warming, the term abrupt climate change ${ }^{[1-3]}$ is used to describe sudden climate change that is detectable over the time-scale of a human lifetime. The feedback loops within the climate system enhance small perturbations and cause a variety of stable states resulting in abrupt climate change. Increase in temperature by $4{ }^{\circ} \mathrm{C}$ to $6{ }^{\circ} \mathrm{C}$ is considered as abrupt climate change.

Anoxic event: It occurs when the Earth's oceans become completely depleted of oxygen $\left(\mathrm{O}_{2}\right)$ below the surface levels. [3]

Climate change and agriculture: Climate change affects agriculture ${ }^{[4]}$ in a number of ways, including through changes in average temperatures, rainfall, and climate extremes (e.g., heat waves); changes in pests and diseases; changes in atmospheric carbon dioxide and ground-level ozone concentrations; changes in the nutritional quality of some foods; and changes in sea level.

Climate change and ecosystems: Unchecked global warming could affect most terrestrial eco regions. Increasing global temperature means that ecosystems ${ }^{[5-7]}$ will change; some species are being forced out of their habitats (possibly to extinction) because of changing conditions, while others are flourishing. Secondary effects of global warming, such as lessened snow cover, rising sea levels, and weather changes, may influence not only human activities but also the ecosystem.

Current sea level rise: Sea level ${ }^{[8]}$ rise has been estimated to be on average $+2.6 \mathrm{~mm}$ and $+2.9 \mathrm{~mm}$ per year $\pm 0.4 \mathrm{~mm}$ since 1993. Additionally, sea level rise has accelerated in recent years 
Drought: Drought ${ }^{[9]}$ is when an area gets less than its normal amount of rain over months or even years. Crops and other plants need water to grow, and land animals need it to live. It can become dangerous to people and other animals; causing famine and even creating deserts. Drought is a natural event, caused by other weather events like El Niño and high pressure systems. Drought can also be triggered by deforestation (people cutting down forests), by global warming, and by diverting rivers or emptying lakes.

Effect on plant biodiversity: Environmental conditions play a key role in defining the function and distribution of plants, in combination with other factors. ${ }^{[10-11]}$ Changes in long term environmental conditions that can be collectively coined climate change are known to have had enormous impacts on plant diversity patterns in the future and are seen as having significant current impacts. It is predicted that climate change will remain one of the major drivers of biodiversity patterns in the future.

Effects on humans: Projected changes in temperature and precipitation under global warming are likely to lead to other effects that threaten human health ${ }^{[12]}$ and safety. For example as the climate changes, the risk of injury, illness, and death from the resulting heat waves, wildfires, intense storms, and floods rise. .

Effects on marine mammals: The effects of climate change on marine mammals ${ }^{[13-14]}$ are of growing concern. The increase of carbon dioxide and other greenhouse gases into the atmosphere is thought to be the main cause of climate change or global warming. Exactly how this will affect the ocean, which is home to marine mammals, is hard to predict since there are many factors, such as weather events and salinity that affect ocean ecosystems.

Environmental migrant: Environmental migrant ${ }^{[15]}$ refers to people who are forced to migrate from or flee their home region due to sudden or long-term changes to their local environment which compromise their well being or secure livelihood, such changes are held to include increased droughts, desertification, sea level rise, and disruption of seasonal weather patterns such as monsoons.

Extinction risk from global warming: The extinction risk ${ }^{[16]}$ of global warming is the risk of species becoming extinct due to the effects of global warming.

Forest dieback: Forest dieback ${ }^{[18]}$ is a condition in trees or woody plants in which peripheral parts are killed, either by parasites or due to conditions like acid rain and drought.

Ocean acidification: Ocean acidification ${ }^{[17]}$ is the ongoing decrease in the $\mathrm{pH}$ of the Earth's oceans, caused by the uptake of carbon dioxide $\left(\mathrm{CO}_{2}\right)$ from the atmosphere. An estimated $30-40 \%$ of the carbon dioxide released by humans into the atmosphere dissolves into oceans, rivers and lakes. To achieve chemical equilibrium, some of it reacts with the water to form carbonic acid. Some of these extra carbonic acid molecules react with a water molecule to give a bicarbonate ion and a hydronium ion, thus increasing ocean acidity $\left(\mathrm{H}^{+}\right.$ion concentration). Between 1751 and 1994 surface ocean $\mathrm{pH}$ is estimated to have decreased representing an increase of almost
$30 \%$ in $\mathrm{H}^{+}$ion concentration in the world's oceans.

Ozone depletion: Ozone depletion ${ }^{[19]}$ describes two distinct but related phenomena observed since the late 1970s:

- a steady decline of about $4 \%$ in the total volume of ozone in Earth's stratosphere (the ozone layer),

- And a much larger springtime decrease in stratospheric ozone around Earth's Polar Regions. The latter phenomenon is referred to as the ozone hole. In addition to these well-known stratospheric phenomena, there are also springtime polar troposphere ozone depletion events.

When CFCs and HCFCs reach the stratosphere, the ultraviolet radiation from the sun causes them to break apart and release chlorine atoms which react with ozone starting chemical cycles of ozone destruction that deplete the ozone layer. One chlorine atom can break apart more than 100,000 ozone molecules.

Regime shift, retreat of glaciers, runway climate change and delayed monsoon are the other important issues related to global warming ${ }^{[20]}[25]$

Regime shift: In ecology, regime shifts ${ }^{[20]}$ are large, abrupt, persistent changes in the structure and function of a system which can be abrupt and difficult to reverse. A regime is a characteristic behavior of a system which is maintained by mutually reinforced processes or feedbacks. Regimes are considered persistent relative to the time period over which the shift occurs. The change of regimes, or the shift, usually occurs when a smooth change in an internal process (feedback) or a single disturbance (external shocks) triggers a completely different system behavior.

Retreat of glaciers: The retreat of glaciers since 1850 affects the availability of fresh water for irrigation and domestic use, mountain recreation, animals and plants that depend on glacier-melt. In the longer term, it affects the level of the oceans. The temporal coincidence of glacier retreat with the measured increase of atmospheric greenhouse gasses is often cited as an evidentiary underpinning of global warming.

Runaway climate change: Runaway climate change or runaway global warming is hypothesized to follow a tipping point in the climate system, after accumulated climate change initiates a reinforcing positive feedback. This is thought to cause climate to rapidly change until it reaches a new stable condition. The term runway climate change is often used with reference to concerns about rapid global warming. Some astronomers use the expression runaway greenhouse effect to describe a situation where the climate deviates catastrophically and permanently from the original state.

Delayed monsoon: Arrival of monsoon depends on ocean temperature and earth's surface temperature. Both these factors are now changing due to global warming resulting in delayed arrival of monsoon. In India, monsoon used to arrive in time on first of June, but in the last decade (2005-2014), it arrived late except in 2013. (Source: Hindustan, 01June 2015) 


\section{REASONS FOR GLOBAL WARMING}

Increasing concentrations of greenhouse gases produced by human activities ${ }^{[21][22][23]}$ is the principal cause of global warming. Carbon dioxide $\left(\mathrm{CO}_{2}\right)$ emissions occur from fossil fuel combustion, cement production, and the use of land for agriculture resulting in deforestation. ${ }^{[24]}$ Human influence is also related to warming of the atmosphere and the ocean, changes in the global water cycle, reductions in snow and ice, global mean sea level rise, and changes in some climate extremes.

\section{Signs OF Climate Change-Global WARMing ${ }^{\text {[25] }}$ \\ - Polar bears are losing their habitats \\ - Sea level is rising \\ - Hurricanes are getting bigger and stronger \\ - Glaciers are melting fast \\ - Temperatures are going up}

\section{ENVIRONMENT POLLUTION AND GLOBAL WARMING}

Climate change/Global warming is the single biggest environmental and humanitarian crisis of our time. The Earth's atmosphere is overloaded with heat-trapping carbon dioxide, which threatens large-scale disruptions in climate with disastrous consequences. We must act now to spur the adoption of cleaner energy sources at home and abroad.

\section{Pollution AND ITS EFFECT ON ENVIRONMENT - A CAUSE OF GREAT CONCERN}

When something gets adulterated to the environment which is very harmful, poisonous or fatal to the animal, people surrounding it and other living things is called as pollution. In simple term pollution is a contamination by a chemical or other pollutant that renders part of the environment unfit for intended or desired use. It is triggered by industrial and commercial waste, agriculture practices, day to day human activities and most notably, modes of transportation and many other sources. Pollution has many forms; it may be chemical substances or energy, such as noise, heat or light.

Pollution always harms humans, pets, plants, trees, and aquatic life. Acid rain, Eutrophication, Ozone depletion, haze and global climate change and crop and forest damage are the major effect of pollution on environment. Pollution always takes away the balance of the fragile ecosystems of earth. Hence we should make all our efforts to control our waste and not to throw it into the ocean or on the land.

\section{EFFECTS OF GLOBAL WARMING}

The effects of an increase in global temperature include a rise in sea levels and a change in the amount and pattern of precipitation, as well as a probable expansion of subtropical deserts Warming is expected to be strongest in the Arctic, with the continuing retreat of glaciers, permafrost and sea ice. Other likely effects of the warming include more frequent extreme weather events including heat waves, droughts and heavy rainfall; ocean acidification; and species extinctions due to shifting temperature regimes. Effects significant to humans include the threat to food security from decreasing crop yields and the loss of habitat from inundation

\section{IMPORTANT ASPECTS OF GLOBAL WARMING}

\section{A. Acid Rain}

Acid rain is the rain that is polluted by acid in the atmosphere. ${ }^{[26]}$ It damages the environment. The acid can also be found in snow and fog. There are two main air pollutants that change into acid, sulfur dioxide $\left(\mathrm{SO}_{2}\right)$ and nitrogen oxide (NOX). When they react with moisture in the atmosphere they become acids. The sulfur and nitrogen pollutants come when fossil fuels are burned in coal-fired generators making electricity, from smelting furnaces in steel works, from petrol driven motor vehicles.

Any other form of precipitation that is unusually acidic possessing elevated levels of hydrogen ions (low $\mathrm{pH}$ ) is also termed as acid rain. It can have harmful effects on plants, aquatic animals and infrastructure.

Water droplets that are unusually acidic because of atmospheric pollution - most notably the excessive amounts of sulfur and nitrogen are categorized as acid rain. Acid rain is also called acid deposition because this term includes other forms of acidic precipitation such as snow.

Acid rain can harm forests and crops. It pollutes rivers, lakes and streams and damages the animals that live in there. Acid rain also damages statues and buildings. Acid in the atmosphere also falls to the earth surface as dust. Scientific studies have revealed that acidic dust particles can cause an increase in attacks of asthma and bronchitis in humans.

When the dust is washed away by rain, the acid is added to the rain water which pours into streams, rivers and the oceans, polluting them and harming plants and animals that live there. Acid rain can also ruin buildings, public statues and monuments as acid eats in to metal and stone.

\section{B. Fossil Fuels}

\section{Special features of fossil fuels ${ }^{[28]}$}

Fossil fuels are made from the remains of ancient plants and animals, buried deep inside the Earth for millions of years. Over a very long period of time, heat and pressure turned these remains into the fossil fuels i.e. coal, oil and natural gas.

Fossil fuels are fuels formed by natural processes such as anaerobic decomposition of buried dead organisms. The age of the organisms and their resulting fossil fuels is typically millions of years, and sometimes exceeds 650 million years. Fossil fuels contain high percentages of carbon and include coal, petroleum and gas. Other more commonly used derivatives of fossil fuels include kerosene and propane. They range from volatile materials with low carbon: hydrogen ratios like methane, to liquid petroleum to nonvolatile materials composed of almost pure carbon, like anthracite coal. Methane can be found in hydrocarbon fields, alone, associated with oil, or in the form of methane clathrates. The theory that fossil fuels formed from the fossilized remains of dead plants by exposure to heat and pressure in the Earth's crust over millions of years. 
When fossil fuels are burned, the carbon stored inside fossil fuels is released into the atmosphere as a gas known as carbon dioxide. Carbon dioxide is a greenhouse gas and is causing global warming. Burning petrol (made from oil) in cars pollutes the air we breathe. Power plants also burn oil and coal to make electricity and release poisonous gases into the air. These gases cause acid rain. Renewable energy is the alternative to using fossil fuels.

\section{Floods}

A flood ${ }^{[29]}$ happens when too much rain falls. Storms can cause floods. In a flood, water from rivers flows over the land. Flood water enters houses and other buildings. A flood happens when too much rain, brought by storms and strong winds, falls and cannot be absorbed by the soil. Rivers burst their banks and the water spills onto the land. Strong winds blowing across the sea make huge waves that surge onto the land and flood coastal areas. There are different types of floods such as River floods, Coastal floods, Flash floods etc.

In other words, a flood is an overflow of water that submerges land which is usually dry. The European Union (EU) Floods Directive defines a flood as a covering by water of land not normally covered by water. In the sense of "flowing water", the word may also be applied to the inflow of the tide. Flooding may occur as an overflow of water from water bodies, such as a river or lake, in which the water overtops or breaks levees, resulting in some of that water escaping its usual boundaries, or it may occur due to an accumulation of rainwater on saturated ground in an area flood. While the size of a lake or other body of water will vary with seasonal changes in precipitation and snow melt, these changes in size are unlikely to be considered significant unless they flood property or drown domestic animals.

Floods can also occur in rivers when the flow rate exceeds the capacity of the river channel, particularly at bends or meanders in the waterway. Floods often cause damage to homes and businesses if they are in the natural flood plains of rivers. While river flood damage can be eliminated by moving away from rivers and other bodies of water, people have traditionally lived and worked by rivers because the land is usually flat and fertile and because rivers provide easy travel and access to commerce and industry.

Some floods develop slowly, while others such as flash floods can develop in just a few minutes and without visible signs of rain. Additionally, floods can be local, impacting a neighborhood or community, or very large, affecting entire river basins.

\section{Ice Ages}

An ice age ${ }^{[30]}$ is a period of long-term reduction in the temperature of Earth's surface and atmosphere, resulting in the presence or expansion of continental and polar ice sheets and alpine glaciers. Within a long-term ice age, individual pulses of cold climate are termed "glacial periods" (or alternatively "glacial" or "glaciations" or colloquially as "ice age"), and intermittent warm periods are called "interglacial". Glaciologically, ice age implies the presence of extensive ice sheets in the northern and southern hemispheres. By this definition, we are in an interglacial period - the Holocene - of the ice age that began 2.6 million years ago at the start of the Pleistocene epoch, because the Greenland, Arctic, and Antarctic ice sheets still exist.

In an ice age a lot of the world is covered by thick ice. It can last for hundreds of years. Big animals lived in the last ice age. Big animals lived in the last ice age. Some were like hairy elephants with huge curved tusks. There were woolly mammoths.

An ice age is thus a period of time when vast sheets of slowly-moving ice cover enormous areas of the earth. When there is a long period of time during which there are several periods of ice age, or glaciations, with warmer periods in between, it is called a glacial epoch.

The last ice age started about 90,000 years ago and ended about 10,000 years ago. It was part of a glacial epoch that started 2 million years ago, called the Pleistocene Epoch. There are many fossils today that tell us of the amazing animals that existed during the Pleistocene era. Together, they are known as mega fauna, and include animals such as woolly mammoths, mastodons, giant beavers, small horses, ground sloths the size of cows, and saber-toothed cats. These became extinct around the end of that era, perhaps because the climate changed rapidly as temperatures rose and the glaciers melted, but also perhaps because of human hunting. Some species survived however and are found today, including wolves, caribou, muskoxen and moose.

http://en.wikipedia.org/wiki/Ice_age

\section{E. Tsunami Tidal Wave}

\section{What is the difference between a Tsunami and a Tidal Wave?}

Although both are sea waves, a tsunami and a tidal wave ${ }^{[31]}{ }^{[32]}$ are two different and unrelated phenomena. A tidal wave is the wave motion of the tides. A tidal wave is a shallow water wave caused by the gravitational interactions between the Sun, Moon, and Earth. ("Tidal wave" was used in earlier times to describe what we now call a tsunami.) Tsunamis are ocean waves triggered by large earthquakes that occur near or under the ocean, volcanic eruptions, submarine landslides, and by onshore landslides in which large volumes of debris fall into the water.

A tsunami also known as a seismic sea wave or as a tidal wave, is a series of waves in a body of water caused by the displacement of a large volume of water, generally in an ocean or a large lake. Earthquakes, volcanic eruptions and other underwater explosions (including detonations of underwater nuclear devices), landslides, glacier calving, meteorite impacts and other disturbances above or below water all have the potential to generate a tsunami. In being generated by the displacement of water, a tsunami contrasts both with a normal ocean wave generated by wind and with tides, which are generated by the gravitational pull of the Moon and the Sun on bodies of water.

Tsunami waves do not resemble normal sea waves, because their wavelength is far longer. Rather than appearing as a breaking wave, a tsunami may instead initially resemble a rapidly rising tide, and for this reason they are often referred to as tidal waves. Tsunamis generally consist of a series of 
waves with periods ranging from minutes to hours, arriving in a so-called "wave train". Wave heights of tens of meters can be generated by large events. Although the impact of tsunamis is limited to coastal areas, their destructive power can be enormous and they can affect entire ocean basins; the 2004 Indian Ocean tsunami was among the deadliest natural disasters in human history with at least 230,000 people killed or missing in 14 countries bordering the Indian Ocean.

Generally, a tsunami is a huge, long wave that comes suddenly and often without warning.

Movement of tsunami: When an earthquake or volcano occurs, the vibrations cause a drop in the sea bed and water floods into the gap. When the gap is full, water rushes back in the opposite direction and creates a long wave At sea, a tsunami is only slightly higher than other waves. A tsunami moves at great speed, up to $800 \mathrm{~km}$ per hour. As it moves nearer to the coast, it slows down and can become higher than 50 meters.

Destruction: By the time the wave reaches the land, it is a high wall of moving water that crashes onto the land. The volume of water and the force of its impact cause huge devastation. It then draws back into the sea again, dragging with it anything in its path.

\section{Solution of Problems Related to Global WARMING}

In order to limit warming to within the lower range, it is necessary to limit the greenhouse gas emissions or enhance the capacity of carbon sinks to absorb GHGs from the atmosphere. Forest's trees, through photosynthesis, absorb and store carbon dioxide. They act as natural air filters. Trees help to control erosion and flooding. It is to be appreciated that one tree consumes 1 ton of carbon dioxide during its lifetime!

\section{A. Mitigation $^{[33-59]}$}

Mitigation means reducing the amount of future climate change. Actions that reduce greenhouse gas (GHG) emissions, or enhance the capacity of carbon sinks to absorb GHGs from the atmosphere are known as mitigation of climate change. Climate mitigation also includes acts to enhance natural sinks, such as reforestation and conservation of forests.

There exists substantial potential for future reductions in emissions by a combination of emission-reducing activities such as energy conservation, increased energy efficiency, and satisfying more of society's power demands with renewable energy and nuclear energy sources. Climate mitigation also includes acts to enhance natural sinks, such as reforestation.

\section{Mitigation strategies}

- Emissions reduction-Carbon credit, Carbon-neutral fuel, Carbon offset, Carbon tax Emissions trading, Fossil-fuel phase-out

- Carbon-free energy-Carbon capture and storage, efficient energy use, Low-carbon economy,

- Nuclear power, Renewable energy

- Others-carbon dioxide removal, carbon sink, climate change mitigation scenarios, climate engineering,
- Reducing emissions by preserving the native forests, trees plantation and urban reforestation

- Programs: Avoiding dangerous climate change, Land allocation, Decision support system

"Carbon free energy" [60] is energy that is produced or generated without producing carbon emissions, which are more accurately referred to as "carbon dioxide emissions." Carbon free energy is typically generated from "renewable energy technologies"

\section{www.CarbonFreeEnergy.com}

\section{i. Low-carbon Power}

Low-carbon power ${ }^{[61]}$ comes from processes or technologies that produce power with substantially lower amounts of carbon dioxide emissions than is emitted from conventional fossil fuel power generation. It includes low carbon power generation sources such as wind power, solar power, and hydropower and, including fuel preparation and decommissioning, nuclear power. The term largely excludes conventional fossil fuel plant sources, and is only used to describe a particular subset of operating fossil fuel power systems, specifically, those that are successfully coupled with a flue gas carbon capture and storage (CCS) system.

\section{ii. $\quad$ Carbon Credit}

A carbon credit ${ }^{[62]}$ is a generic term for any tradable certificate or permit representing the right to emit one tone of carbon dioxide or the mass of another greenhouse gas with a carbon dioxide equivalent $\left(\mathrm{tCO}_{2} \mathrm{e}\right)$ equivalent to one tone of carbon dioxide.

Carbon credits and carbon markets are a component of national and international attempts to mitigate the growth in concentrations of greenhouse gases (GHGs). One carbon credit is equal to one tone of carbon dioxide, or in some markets, carbon dioxide equivalent gases. Carbon trading is an application of an emissions trading approach. Greenhouse gas emissions are capped and then markets are used to allocate the emissions among the group of regulated sources.

The goal is to allow market mechanisms to drive industrial and commercial processes in the direction of low emissions or less carbon intensive approaches than those used when there is no cost to emitting carbon dioxide and other GHGs into the atmosphere. Since GHG mitigation projects generate credits, this approach can be used to finance carbon reduction schemes between trading partners and around the world.

There are also many companies that sell carbon credits to commercial and individual customers who are interested in lowering their carbon footprint on a voluntary basis. These carbons off setters purchase the credits from an investment fund or a carbon development company that has aggregated the credits from individual projects. Buyers and sellers can also use an exchange platform to trade, such as the Carbon Trade Exchange, which is like a stock exchange for carbon credits. The quality of the credits is based in part on the validation process and sophistication of the fund or development company that acted as the sponsor to the carbon project. This is reflected in their price; voluntary units typically have less value than the units sold through the 
rigorously validated Clean Development Mechanism.

\section{iii. Carbon Offset}

A carbon offset is a reduction in emissions of carbon dioxide or greenhouse gases made in order to compensate for or to offset an emission made elsewhere.

Carbon offsets ${ }^{[63]}$ are measured in metric tons of carbon dioxide-equivalent $\left(\mathrm{CO}_{2} \mathrm{e}\right)$ and may represent six primary categories of greenhouse gases:carbon dioxide $\left(\mathrm{CO}_{2}\right)$, methane $\left(\mathrm{CH}_{4}\right)$, nitrous oxide $\left(\mathrm{N}_{2} \mathrm{O}\right)$, per fluorocarbons (PFCs), hydro fluorocarbons (HFCs), and sulfur hexafluoride $\left(\mathrm{SF}_{6}\right)$. One carbon offset represents the reduction of one metric ton of carbon dioxide or its equivalent in other greenhouse gases.

There are two markets for carbon offsets:

- Larger compliance market

- Smaller voluntary market

In the larger, compliance market, companies, governments, or other entities buy carbon offsets in order to comply with caps on the total amount of carbon dioxide they are allowed to emit. This market exists in order to achieve compliance with obligations of Annex 1-Parties under the Kyoto Protocol, and of liable entities under the EU Emission Trading Scheme. In 2006 , about $\$ 5.5$ billion of carbon offsets were purchased in the compliance market, representing about 1.6 billion metric tons of $\mathrm{CO}_{2}$ e reductions.

In the much smaller, voluntary market, individuals, companies, or governments purchase carbon offsets to mitigate their own greenhouse gas emissions from transportation, electricity use, and other sources. For example, an individual might purchase carbon offsets to compensate for the greenhouse gas emissions caused by personal air travel. Many companies offer carbon offsets as an up-sell during the sales process so that customers can mitigate the emissions related with their product or service purchase (such as offsetting emissions related to a vacation flight, car rental, hotel stay, consumer good, etc.). In 2008, about $\$ 705$ million of carbon offsets were purchased in the voluntary market, representing about 123.4 million metric tons of $\mathrm{CO}_{2} \mathrm{e}$ reductions.

Offsets are typically achieved through financial support of projects that reduce the emission of greenhouse gases in the short- or long-term. The most common project type is renewable energy, such as wind farms, biomass energy, or hydroelectric dams. Others include energy efficiency projects, the destruction of industrial pollutants or agricultural byproducts, destruction of landfill methane, and forestry projects. Some of the most popular carbon offset projects from a corporate perspective are energy efficiency and wind turbine projects.

Carbon offsetting has gained some appeal and momentum mainly among consumers in western countries who have become aware and concerned about the potentially negative environmental effects of energy-intensive lifestyles and economies. The Kyoto Protocol has sanctioned offsets as a way for governments and private companies to earn carbon credits that can be traded on a market place. The protocol established the Clean Development Mechanism (CDM), which validates and measures projects to ensure they produce authentic benefits and are genuinely "additional" activities that would not otherwise have been undertaken. Organizations that are unable to meet their emissions quota can offset their emissions by buying CDM-approved Certified Emissions Reductions.

Offsets may be cheaper or more convenient alternatives to reducing one's own fossil-fuel consumption. However, some critics object to carbon offsets, and question the benefits of certain types of offsets. Due diligence is recommended to help businesses in the assessment and identification of "good quality" offsets to ensure offsetting provides the desired additional environmental benefits, and to avoid reputational risk associated with poor quality offsets.

Offsets are viewed as an important policy tool to maintain stable economies. One of the hidden dangers of climate change policy is unequal prices of carbon in the economy, which can cause economic collateral damage if production flows to regions or industries that have a lower price of carbon - unless carbon can be purchased from that area, which offsets effectively permit, equalizing the price.

\section{Carbon-neutral fuel [64]}

Carbon-neutral fuels can refer to a variety of energy fuels or energy systems which have no net greenhouse gas emissions or carbon footprint. One class is synthetic fuel (including methane, gasoline, diesel fuel, jet fuel or ammonia produced from sustainable or nuclear energy used to hydrogenate waste carbon dioxide recycled from power plant flue exhaust gas or derived from carbonic acid in seawater. Other types can be produced from renewable energy sources such as wind turbines, solar panels, and hydroelectric power plants. Such fuels are potentially carbon-neutral because they do not result in a net increase in atmospheric greenhouse gases. Until captured carbon is used for plastics feedstock, carbon neutral fuel synthesis is the primary means of carbon capture and utilization or recycling.

To the extent that carbon-neutral fuels displace fossil fuels, or if they are produced from waste carbon or seawater carbonic acid, and their combustion is subject to carbon capture at the flue or exhaust pipe, they result in negative carbon dioxide emission and net carbon dioxide removal from the atmosphere, and thus constitute a form of greenhouse gas remediation.

\section{iv. Emissions Trading ${ }^{[65]}$}

Emissions trading or cap and trade ("cap" meaning a legal limit on the quantity of a certain type of chemical an economy can emit each year) is a market-based approach used to control pollution by providing economic incentives for achieving reductions in the emissions of pollutants. Various countries have adopted emission trading systems as one of the strategies for mitigating climate-change by addressing international greenhouse-gas emission.

Examples of mitigation include switching to low-carbon energy sources, such as renewable and nuclear energy, and expanding forests and other "sinks" to remove greater amounts of carbon dioxide from the atmosphere. Energy efficiency may 
also play a role. Another approach to climate change mitigation is climate engineering.

Responding to climate change involves a two-pronged approach:

- Reducing emissions of and stabilizing the levels of heat-trapping greenhouse gases in the atmosphere ("mitigation");

- Adapting to the climate change already in the pipeline ("adaptation").

In order to effectively address the threat of global warming, we must significantly reduce the amount of heattrapping emissions we are putting into the atmosphere. A comprehensive set of climate solutions are listed below:

- Expand the use of renewable energy and transform our energy system to one that is cleaner and less dependent on coal and other fossil fuels.

- Increase vehicle fuel efficiency and support other solutions that reduce U.S. oil use. Place limits on the amount of carbon that polluters are allowed to emit.

- Build a clean energy economy by investing in efficient energy technologies, industries, and approaches.

- Reduce tropical deforestation and its associated global warming emissions.

A wide array of adaptation options is available, but more extensive adaptation than is currently occurring is required to reduce vulnerability to climate change.

\section{B. Adaptation ${ }^{[66-70]}$}

Adaptation to climate change means taking action to minimize risks and maximize opportunities resulting from climate change. Adaptation responses include actions to reduce the impacts of extreme weather events, and enhance the resilience of households, communities, businesses, and urban and rural environments.

Proposed adaptations-strategies: Glacial lakes desalination, Drought tolerance Irrigation investment, Rainwater storage, Sustainable development and Weather modification. Other policy responses include adaptation to climate change.

A concept related to adaptation is "adaptive capacity", which is the ability of a system (human, natural or managed) to adjust to climate change (including climate variability and extremes) to moderate potential damages, to take advantage of opportunities, or to cope with consequences.

Adaptation to global warming is a response to global warming that seeks to reduce the vulnerability of social and biological systems to current climate change and thus offset the effects of global warming. Even if emissions are stabilized relatively soon, global warming and its effects will last many years, and adaptation will be necessary to the resulting changes in climate. Adaptation is especially important in developing countries since those countries are predicted to bear the brunt of the effects of global warming. That is, the capacity and potential for humans to adapt (called adaptive capacity) is unevenly distributed across different regions and populations, and developing countries generally have less capacity to adapt. Adaptive capacity is closely linked to social and economic development (IPCC,2007).

The economic costs of adaptation to climate change are likely to cost billions of dollars annually for the next several decades, though the amount of money needed is unknown. Donor countries promised an annual $\$ 100$ billion by 2020 through the Green for developing countries to adapt to climate change. However, while the fund was set up during COP16 in Cancun, concrete pledges by developed countries have not been forthcoming. The adaptation challenge grows with the magnitude and the rate of climate change.

\section{Key Adaptation Terms}

Adaptation - Adjustment in natural or human systems to a new or changing environment that exploits beneficial opportunities or moderates negative effects.

Adaptive capacity: The ability of a system to adjust to climate change (including climate variability and extremes) to moderate potential damages, to take advantage of opportunities, or to cope with the consequences.

Resilience: A capability to anticipate, prepare for, respond to, and recover from significant multi hazard threats with minimum damage to social well-being, the economy, and the environment.

Vulnerability: The degree to which a system is susceptible to, or unable to cope with, adverse effects of climate change, including climate variability and extremes. Vulnerability is a function of the character, magnitude, and rate of climate variation to which a system is exposed, its sensitivity, and its adaptive capacity.

"Adaptation" refers to efforts by society or ecosystems to prepare for or adjust to future climate change. These adjustments can be protective (i.e., guarding against negative impacts of climate change), or opportunistic (i.e., taking advantage of any beneficial effects of climate change).

Mitigation: reducing climate change - involves reducing the flow of heat-trapping greenhouse gases into the atmosphere, either by reducing sources of these gases (for example, the burning of fossil fuels for electricity, heat or transport) or enhancing the "sinks" that accumulate and store these gases (such as the oceans, forests and soil). The goal of mitigation is to avoid dangerous human interference with the climate system, and "stabilize greenhouse gas levels in a timeframe sufficient to allow ecosystems to adapt naturally to climate change, ensure that food production is not threatened and to enable economic development to proceed in a sustainable manner"

\section{Examples of Adaptation}

Adaptation can consist of a wide variety of actions by an individual, community, or organization to prepare for, or respond to, climate change impacts. Many of these measures are things we are already doing but could be stepped up or modified to prepare for climate change. Some examples include: 


\section{Agriculture and Food Supply}

- Breed crop varieties that are more tolerant of heat, drought, and water logging from heavy rainfall or flooding

- Protect livestock from higher summer temperatures by providing more shade and improving air flow in barns'

Coasts

- Promote shore protection techniques and open space preserves that allow beaches and coastal wetlands to gradually move inland as sea level rises.

- Identify and improve evacuation routes and evacuation plans for low-lying areas, to prepare for increased storm surge and flooding. ${ }^{[4]}$

\section{Ecosystems}

- Protect and increase migration corridors to allow species to migrate as the climate changes.

- Promote land and wildlife management practices that enhance ecosystem resilience

\section{Energy}

- Increase energy efficiency to help offset increases in energy consumption.

- Harden energy production facilities to withstand increased flood, wind, lightning, and other stormrelated stresses.

\section{Human Health}

- Implement early warning systems and emergency response plans to prepare for changes in the frequency, duration, and intensity of extreme weather events.

- Plant trees and expand green spaces in urban settings to moderate heat increases. ${ }^{[4]}$

\section{Water Resources}

- Improve water use efficiency and build additional water storage capacity.

- Protect and restore stream and river banks to ensure good water quality and safe guard water quantity.

\section{Geothermal Energy}

Geothermal energy ${ }^{[71]}$ is the heat from the Earth. It is clean, sustainable and does not pollute. Resources of geothermal energy range from the shallow ground to hot water and hot rock found a few miles beneath the Earth's surface, and down even deeper to the extremely high temperatures of molten rock called magma.

Geothermal energy is the force that causes volcanoes to erupt. The heat energy combines with water to produce steam and hot water which can be used as geothermal power to heat buildings and to generate electricity. It is renewable because it is always being produced inside the earth.

http://www.renewableenergyworld.com/geothermal-energy/tech.html

\section{Solar Energy}

In solar energy, ${ }^{[72]}$ Solar panels trap the Sun's energy. It is the energy of sunlight collected and used to provide electricity, to heat water, and to heat or cool homes, businesses or industry. Sunlight is a clean, renewable source of energy. It is a sustainable resource, meaning it doesn't run out, but can be maintained because the sun shines almost every day. Now a day there is growing interests in using clean, renewable energy such as solar, wind, geothermal steam and others. It is called 'Green Power'.

\section{E. Renewable Energy}

Renewable energy ${ }^{[73]}$ is any form of energy that comes from natural sources such as: sunlight to produce solar electricity; wind to produce wind power; rainwater to produce hydro-electricity, the tides or waves for tidal power. These sources of energy will never run out. These are supplied or replaced by nature and are always available.

Geothermal energy is the heat that comes from inside the Earth- the steam and hot water is used to produce geothermal power. Bio-fuels such as ethanol can be produced from sugar cane and other crops to replace petrol as the energy for cars and trucks and other forms of transport. Biomass is energy that comes from wood, garbage and waste from farms and farm animals.

Renewable energy has minimum impact on the environment and doesn't release dangerous greenhouse gases into the atmosphere that are said to be the cause for global warming or climate change. The power of the tides can be used to generate electrical energy.

\section{F. Trees Plantation and Conservation of Forests}

Plantation of trees and conservation of native forests are very helpful in mitigating the problems related to global warming. Green plants absorb sunlight, breathe in carbon dioxide, absorb water and manufacture food products while breathing out oxygen for all living organisms. This process is known as photosynthesis and the food that plants produce is chemical energy that we humans can eat including sugars of all varieties. A great emphasis is placed on trees in maintaining the ecological balance. They form important links in the earth's geological, chemical, and hydrological cycles by [74]:

- Taking in $\mathrm{CO}_{2}$ and releasing oxygen;

- Releasing carbon and mineral elements such as nitrogen and phosphorus (important in plant growth) as they decay;

- Absorbing moisture for growth and releasing it as vapor through transpiration;

- Preventing erosion by reducing the force of rainfall at the soil surface and by intercepting and absorbing water, rather than allowing it to run off directly;

- Harboring a diversity of wildlife;

- Acting as windbreaks;

- Providing us with shade and beauty on a largely agricultural and urban landscape.

Forests perform various ecological and environmental functions. By fixing carbon they help maintain the atmospheric carbon dioxide levels low and counteract the global "greenhouse" effect. The great beauty and inspirational qualities of forests lie in their important biological tasks. By 
producing vast amounts of oxygen and water vapor, and absorbing carbon dioxide, they help support all life on Earth. ${ }^{[75]}$ Forests benefited people by:

- Providing fertile soil for good and fast growing of crops.

- $\quad$ Providing enough oxygen for the survival of species by absorbing carbon dioxide and changing it to oxygen.

- Absorbing carbon dioxide also reduces greenhouse effects, thus reducing Global warming.

It is to be mentioned that economy of India would be sound if at least one-third (30-33\%) of country's land comes under forest. ${ }^{[76]}$ To achieve this, there should be prompt action at the levels of individuals, community and the government for reducing the adverse effects of global warming.

\section{CONCLUSION}

- Global warming is the single biggest environmental and humanitarian crisis of the present time. The Earth's atmosphere is overloaded with heat-trapping carbon dioxide, which threatens large-scale disruptions in climate with disastrous consequences. The whole world is being compelled to act now to spur the adoption of cleaner energy sources at home and abroad.

- In order to limit global warming to within the lower range, it will be necessary to adopt policies that will limit greenhouse gas emissions to one of several significantly different scenarios. This will become more and more difficult with each year of increasing volumes of emissions and even more drastic measures will be required in later years to stabilize a desired atmospheric concentration of greenhouse gases. Increase in forest cover to one-third of total land area (33\%) is essentially required to limit the greenhouse gas emission and keeping emissions under control.

- A great emphasis is placed on trees plantations in maintaining the ecological balance. They form important links in the earth's geological, chemical, and hydrological cycles.

- Plantation of trees and conservation of native forests are very helpful in mitigating the problems related to global warming. Forests and trees act as natural sinks for $\left(\mathrm{CO}_{2}\right)$ emissions. Forests do perform various ecological, environmental and biological functions. By producing vast amounts of oxygen and water vapor, and absorbing carbon dioxide, they help support all life on Earth.

- Now a day there is growing interests in using clean, renewable energy such as solar, wind, geothermal, tidal wave, steam and others. It is called 'Green Power'. Renewable energy has minimum impact on the environment and doesn't release dangerous greenhouse gases into the atmosphere.

- A concept related to adaptation is "adaptive capacity", which is the ability of a system to adjust to climate change/global warming to moderate potential damages, take advantage of opportunities, or to cope with consequences.

\section{ACKNOWLEDGEMENT}

Subject matters and technical contents of the article "Global warming: Problems Issues Corrective measures" are principally based on the published literatures available on the Internet Websites. Author acknowledges with regards all those whose publications have been referred and utilized in the preparation of this particular feature article

Assistance from Mr. S P Tripathi, Head and National WHS Manager, QBE, Australia is also duly acknowledged.

\section{RESOURCES}

\section{Potential Issues and Effects}

[1] http://en.wikipedia.org/wiki/Effects_of_global_warming

[2] http://en.wikipedia.org/wiki/Climate_change_and_ecosystems

[3] en.wikipedia.org/wiki/Abrupt_climate_changeen.wikipedia.org/wiki/An oxic_event

[4] en.wikipedia.org/wiki/Climate_change_and_agriculture

[5] www.epa.gov/climatechange/impacts-adaptation/ecosystems.html

[6] www.epa.gov/climatechange/Downloads/Climate_Change_Ecosystems. pdf

[7] en.wikipedia.org/wiki/Climate_change_and_ecosystems

[8] en.wikipedia.org/wiki/Current_sea_level_rise

[9] simple.wikipedia.org/wiki/Drought

[10] en.wikipedia.org/wiki/Effect_of_climate_change_on_plant_biodiversity

[11] bioenv.gu.se/digitalAssets/1432/1432197_fantahun.pdf

[12] en.wikipedia.org/wiki/Effects_of_global_warming_on_human_health

[13] The Effects of Ocean Pollution on Marine Mammals - Blue ...

[14] www.bluevoice.org/news_issueseffects.php

[15] en.wikipedia.org/wiki/Environmental_migrant

[16] en.wikipedia.org/wiki/Extinction_risk_from_global_warming

[17] en.wikipedia.org/wiki/Fisheries_and_climate_change (Increase in ocean temperature and ocean acidification)

[18] en.wikipedia.org/wiki/Forest_dieback

[19] en.wikipedia.org/wiki/Ozone_depletion

[20] www.stockholmresilience.org/21/research/research.../regime-shifts.html

[21] http://en.wikipedia.org/wiki/Global_warming\#cite_note-7

[22] http://en.wikipedia.org/wiki/Global_warming\#cite_note-8

[23] http://en.wikipedia.org/wiki/Global_warming\#cite_note-9

[24] http://en.wikipedia.org/wiki/Global_warming\#cite_note-11

[25] http://en.wikipedia.org/wiki/Global_warming

[26] http://en.wikipedia.org/wiki/Acid_rain

[27] http://geography.about.com/od/globalproblemsandissues/a/acidrain.htm

[28] http://en.wikipedia.org/wiki/Fossil_fuel

[29] http://en.wikipedia.org/wiki/Flood

[30] http://en.wikipedia.org/wiki/Ice_age

[31] http://en.wikipedia.org/wiki/Tsunami

[32] http://www.usgs.gov/faq/categories/9755/3141

\section{Mitigation}

[33] http://en.wikipedia.org/wiki/Climate_change_mitigation

[34] www.ucsusa.org./global-warming/...global-warming-solutions-reduce-...

[35] en.wikipedia.org/wiki/Climate_change_mitigation

[36] www.huffingtonpost.com/.../carbonfree-energy-is-poss_b_4486153.html

[37] www.truth-out.org/.../18134-carbon-free-nuclear-free-energy-economy-

[38] www.carbon-free-energy.com/

[39] en.wikipedia.org/wiki/Low-carbon_power

[40] en.wikipedia.org/wiki/Carbon_credit 
[41] en.wikipedia.org/wiki/Carbon_offset

[42] en.wikipedia.org/wiki/Carbon-neutral_fuel

[43] en.wikipedia.org/wiki/Emissions_trading

[44] https://sites.google.com/.../carbon-tax-needed-not-cap-and-tradeemissio.

[45] www.carbontax.org/faqs/

[46] www.mass.gov/eea/docs/doer/fuels/mass-carbon-tax-study.pdf

[47] https://climatechangesocialchange.wordpress.com/category/carbonoffsets/

[48] www.policyalternatives.ca/sites/.../CCPA-C_Fair_Effective_Carbon.pdf

[49] www.hks.harvard.edu/.../Aldy\%20\&\%20Stavins\%20Pricing\%20Carbon.

[50] en.wikipedia.org/wiki/Low-carbon_power

[51] en.wikipedia.org/wiki/Low-carbon_economy

[52] en.wikipedia.org/wiki/Energy_policy_of_the_United_Kingdom

[53] www.world-nuclear.org/info/Energy-and.../-Clean-Coal--Technologies/

[54] policy.greenparty.org.uk/ey.html

[55] newclimateeconomy.report/energy/

[56] https://www.ipcc.ch/pdf/assessment-report/ar4/.../ar4-wg3-chapter4.pdf (IPCC Energy supply)

[57] https://www.gov.uk/government/uploads/.../1358-the-carbon-plan.pdf

[58] https://www.iop.org/publications/iop/archive/file_52050.pdf

[59] www.eonenergy.com > ... > Decentralized energy experts

[60] http://carbonfreeenergy.com/

[61] http://en.wikipedia.org/wiki/Low-carbon_power

[62] http://en.wikipedia.org/wiki/Carbon_credit

[63] http://en.wikipedia.org/wiki/Carbon_offset

[64] http://en.wikipedia.org/wiki/Carbon-neutral_fuel

[65] http://en.wikipedia.org/wiki/Emissions_trading

\section{Adaptation}

[66] en.wikipedia.org/wiki/Adaptation_to_global_warmingStrategies to adapt to an uncertain climate change

[67] S Hallegatte - Global Environmental Change, 2009 - Elsevier

[68] http://www.ucsusa.org/our-work/global-warming/solutions/globalwarming-solutions-reduce-emissions\#.VSYv_9yUfAo (Clean white smoke)

[69] http://environment.nationalgeographic.com/environment/globalwarming/gw-effects

[70] http://en.wikipedia.org/wiki/Adaptation_to_global_warming

[71] http://www.renewableenergyworld.com/geothermal-energy/tech.html

[72] http://www.renewableenergyworld.com/solar-energy/tech.html

[73] http://www.renewableenergyworld.com/index/tech.htm

[74] http://www.museum.state.il.us/muslink/forest/htmls/gloss1.htm

[75] http://www.tutorvista.com/biology/conservation-of-forest-and- wildlife

[76] http://en.wikipedia.org/wiki/Environmental_issues_in_India\#cite_notemoef $35-58$

\section{Images}

[77] http://upload.wikimedia.org/wikipedia/commons/a/a2/Effects_of_global _warming,_plotted_against_changes_in_global_mean_temperature.png

[78] http://upload.wikimedia.org/wikipedia/commons/2/2b/Energy_change_i nventory,_1971-2010.svg

[79] http://upload.wikimedia.org/wikipedia/commons/a/a4/Annual_world_gr eenhouse_gas_emissions,_in_2005,_by_sector.svg

[80] http://upload.wikimedia.org/wikipedia/commons/e/e0/Greenhouse_Gas_ by_Sector.png

[81] http://www.rainharvest.co.za/wp-content/uploads/2010/10/globalwarming-causes-and-effects.jpg

[82] http://i.dailymail.co.uk/i/pix/2011/09/13/article-0-0DE026E100000578177_634x381.jpg
[83] http://lunar.thegamez.net/greenenergyimage/environmentalconsequences-of-sources-of-energy/life-cycle-assessment-lca-nexans500x300.jpg

[84] https://lakotascorner.files.wordpress.com/2011/03/ghouse_effect.jpg

[85] http://lunar.thegamez.net/greenenergyimage/what-is-green-informationtechnology/what-is-climate-change-green-facts-global-challenges-qahome-climate-700x558.jpg

[86] http://www.skepticalscience.com/graphics/human_fingerprints.jpg

[87] https://marchantscience.wikispaces.com/file/view/greenhouse_effect.gif/ 77237967/greenhouse_effect.gif

[88] www.theworldofenergy.com500 $\times 373$ Search by image

[89] https://marchantscience.wikispaces.com/file/view/greenhouse_effect.gif/ 77237967/greenhouse_effect.gif

[90] http://upload.wikimedia.org/wikipedia/commons/e/e8/Impacts_of_Globa 1_Warming.png

[91] http://www.ecifm.rdg.ac.uk/climat2.gif

[92] www.theworldofenergy.com $500 \times 373$ Search by image

[93] http://www.weatherquestions.com/greenh ouse-effect- simplified.jpg

[94] http://www.epa.gov/ozone/science/images/process.gif

[95] www.ucsusa.org

[96] http://www.ucsusa.org/sites/default/files/styles/large/public/images/2014 /08/energy-coal-power-plant-with-smokestacks-and-coolingtowers.jpg?itok=oFXZMn2s

[97] chindianquotes.blogspot.com512 $\times 512$ Search by image

[98] https://s-media-cacheak0.pinimg.com/236x/31/08/a1/3108a1b726ad0e9262fc0f32538d0c9e.jp

[99] https://s-media-cacheak0.pinimg.com/236x/31/08/a1/3108a1b726ad0e9262fc0f32538d0c9e.jp $\mathrm{g}$

[100]https://ikjotsidhu.files.wordpress.com/2010/08/earth-and-trees.jpg

[101]http://thumb101.shutterstock.com/display_pic_with_logo/2724652/2504 24107/stock-vector-stop-global-warming-animal-planet-250424107.jpg

\section{AUTHOR PROFILE}

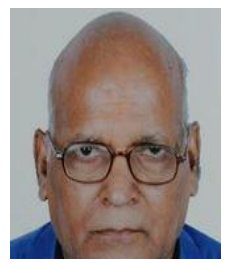

B D Pandey, Ex Researcher, R\&D Tata Steel, Jamashedur, India

Mr. B D Pandey Graduated in Metallurgical Engineering in1967, obtained degree of M. Tech (Ferrous Metallurgy) in 1981 from NIT (then RIT) Jamshedpur. He joined Tata Steel (R\&D) in June 1970 and retired as Researcher in February 2004 after serving Tata Steel for 34 years. As a Researcher he headed the Iron-making process Research in $\mathrm{R} \& \mathrm{D}$. His areas of specialization are Iron-Making, Direct Reduction, Value added Ferroalloys.

To his credit, Mr. Pandey has about 100 publications in the National and International Journals of repute. He is the Recipient of S. Vishwanathan Medal (1994) for the best paper in Tata Search, Visvesvaraya Gold Medal (1996-1997), SAIL Gold Medal (1997-1998). He is the Co-author of an Engineering Book "Metallic for Steel making- production and use". Mr. Pandey enjoys publishing his research findings. In BYBF (Beyond the Blast Furnace) another engineering book published by the CRC Press America, Mr., Pandey contributed substantially through his research findings.

Mr. Pandey loves Nature. Natural phenomena / events are very close to his heart.

Besides applied research, Mr. Pandey worked in the areas of Business Process Re-engineering (Total Quality Management, Knowledge Management - lead expert, Total Operational Performance, Environment and Safety). 
IMAGES: Salient Features-Global Warming Problems Issues Corrective Measures

\section{Summary of global warming impacts}

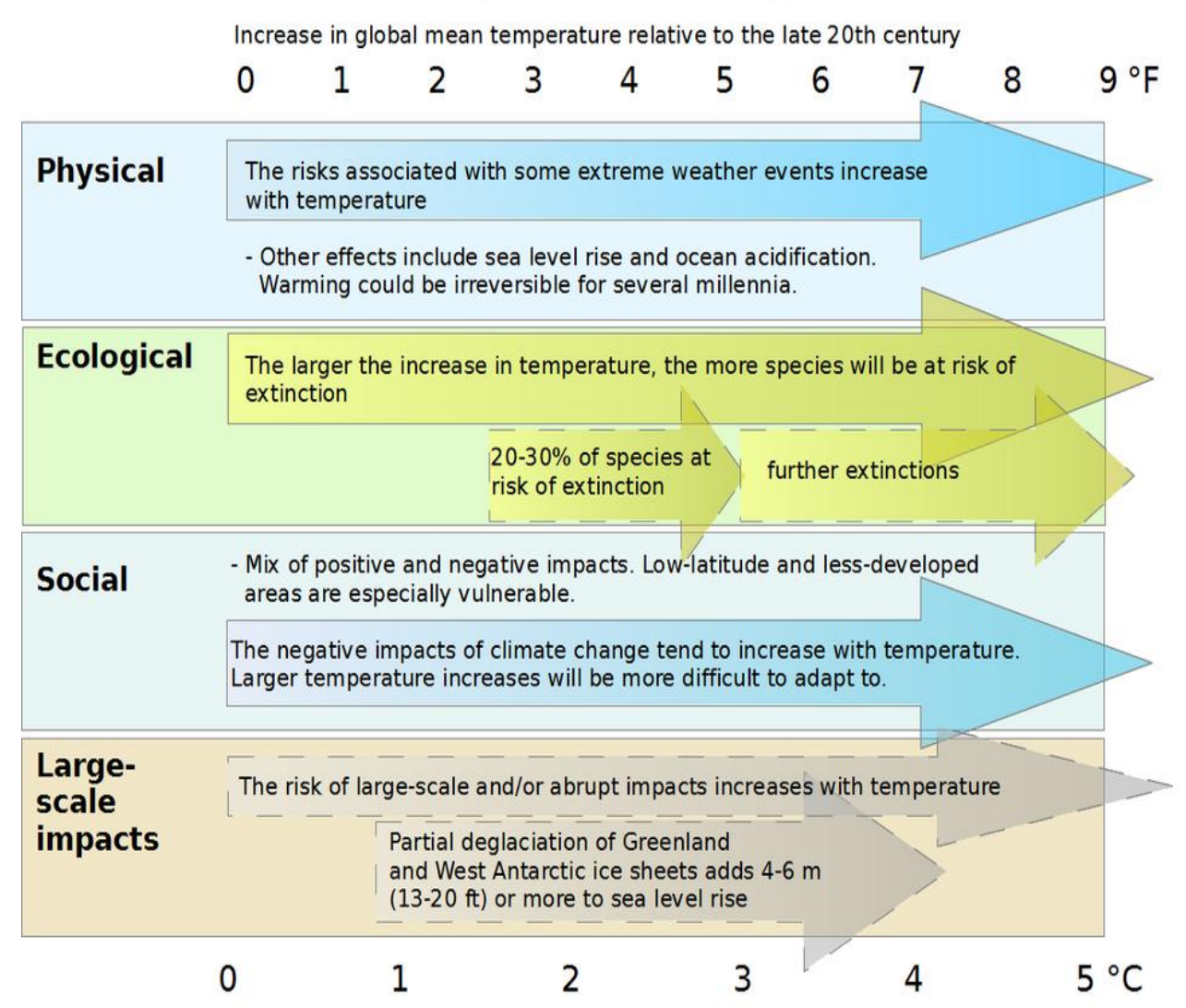

Image 1: Effects of Global Warming, Plotted against Changes in Global Mean Temperature.png ${ }^{\text {[77] }}$

Energy change inventory, 1971-2010

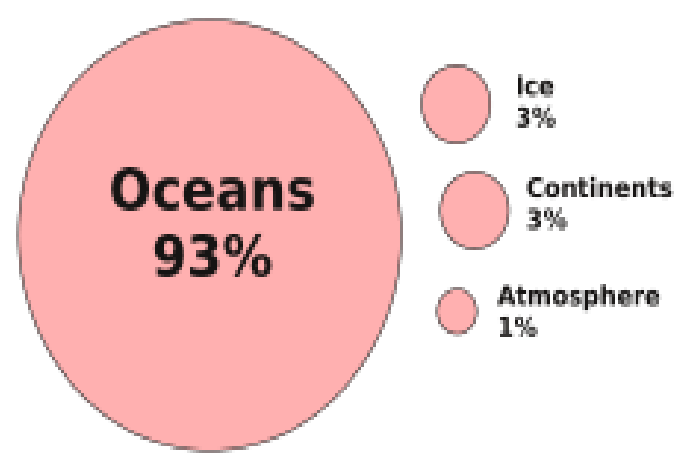

Image 2: Energy Change Inventory(1971-2010)

The above data (Bubble graph) shows how the extra energy trapped mainly by anthropogenic greenhouse gases has been distributed on the Earth between 1971 and 2010: Most of this extra energy has been absorbed by the oceans. ${ }^{78}$ 


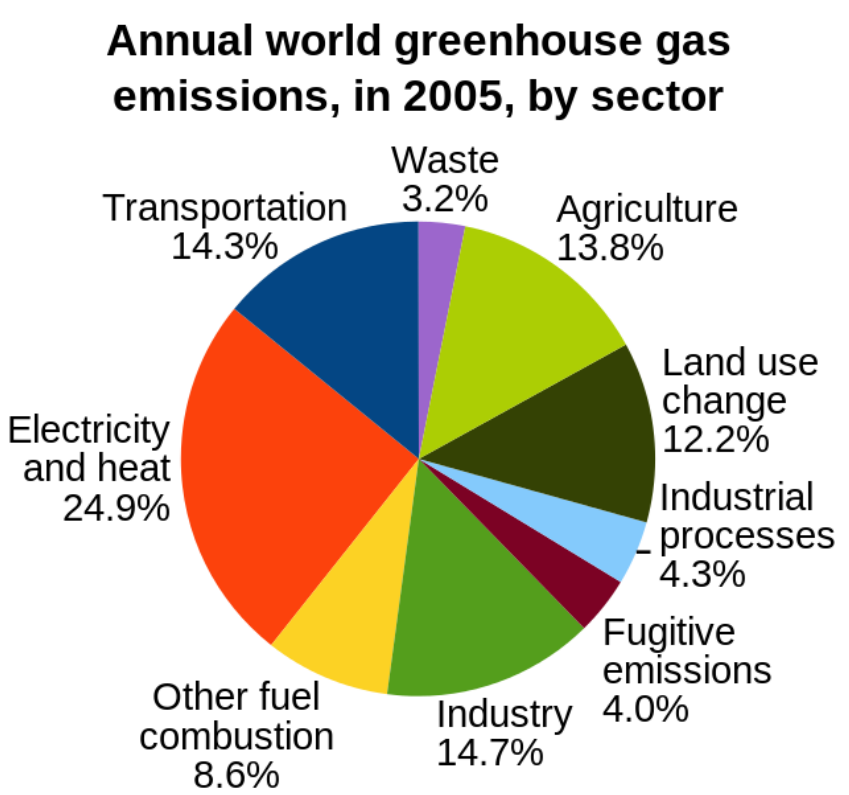

Image 3: Greenhouse Gas Emissions in 2005 by Different Sector. ${ }^{[79]}$

\section{Annual Greenhouse Gas Emissions by Sector}

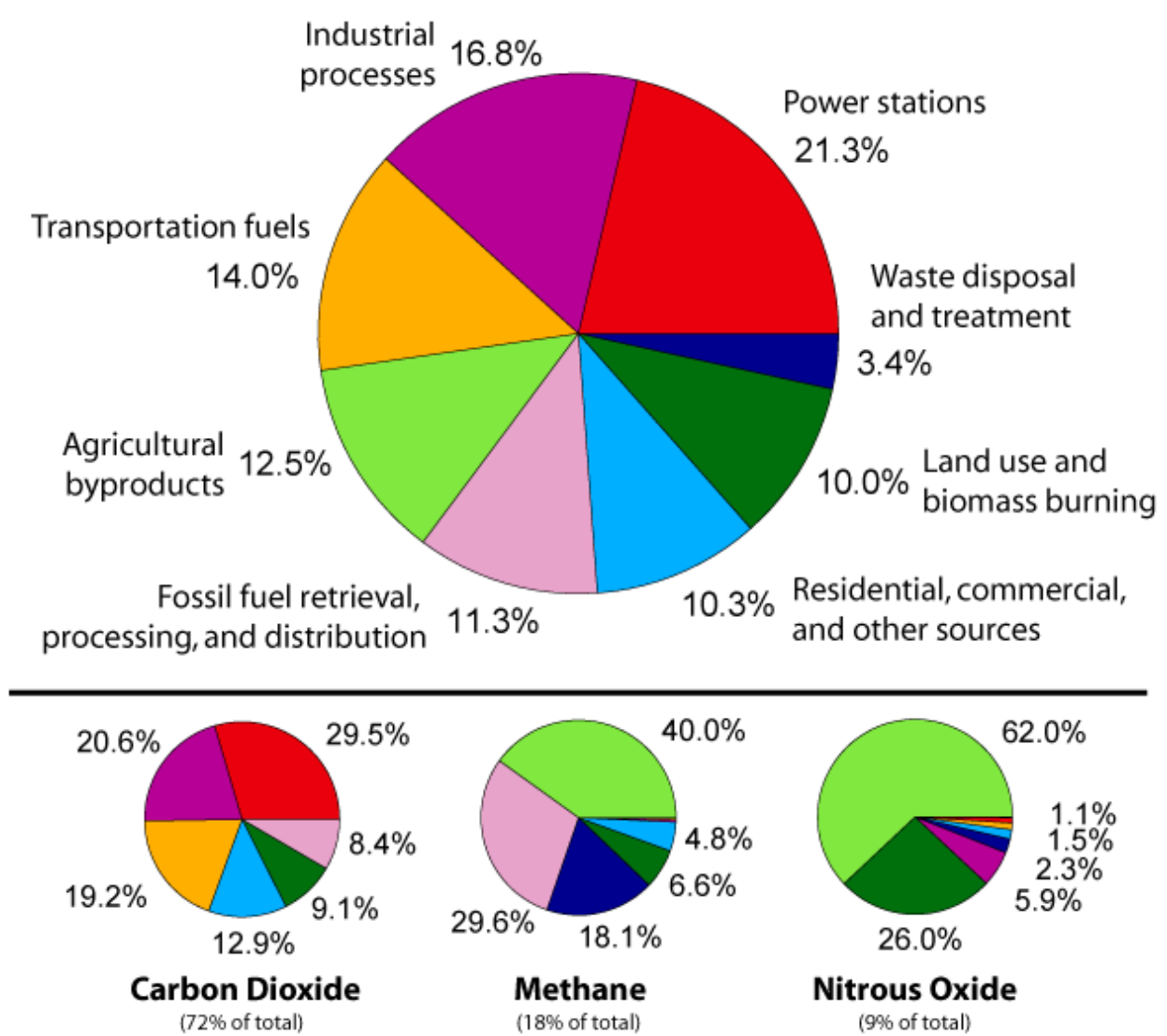

Image 4: Annual Greenhouse ga s Emissions by Fifferent Sector ${ }^{[80]}$

In order to limit global warming to within the lower range it will be necessary to adopt policies that will limit greenhouse gas emissions to one of several significantly different scenarios. This will become more and more difficult with each year of increasing volumes of emissions and even more drastic measures will be required in later years to stabilize a desired atmospheric concentration of greenhouse gases. 


\section{Global warming: Causes and effects}

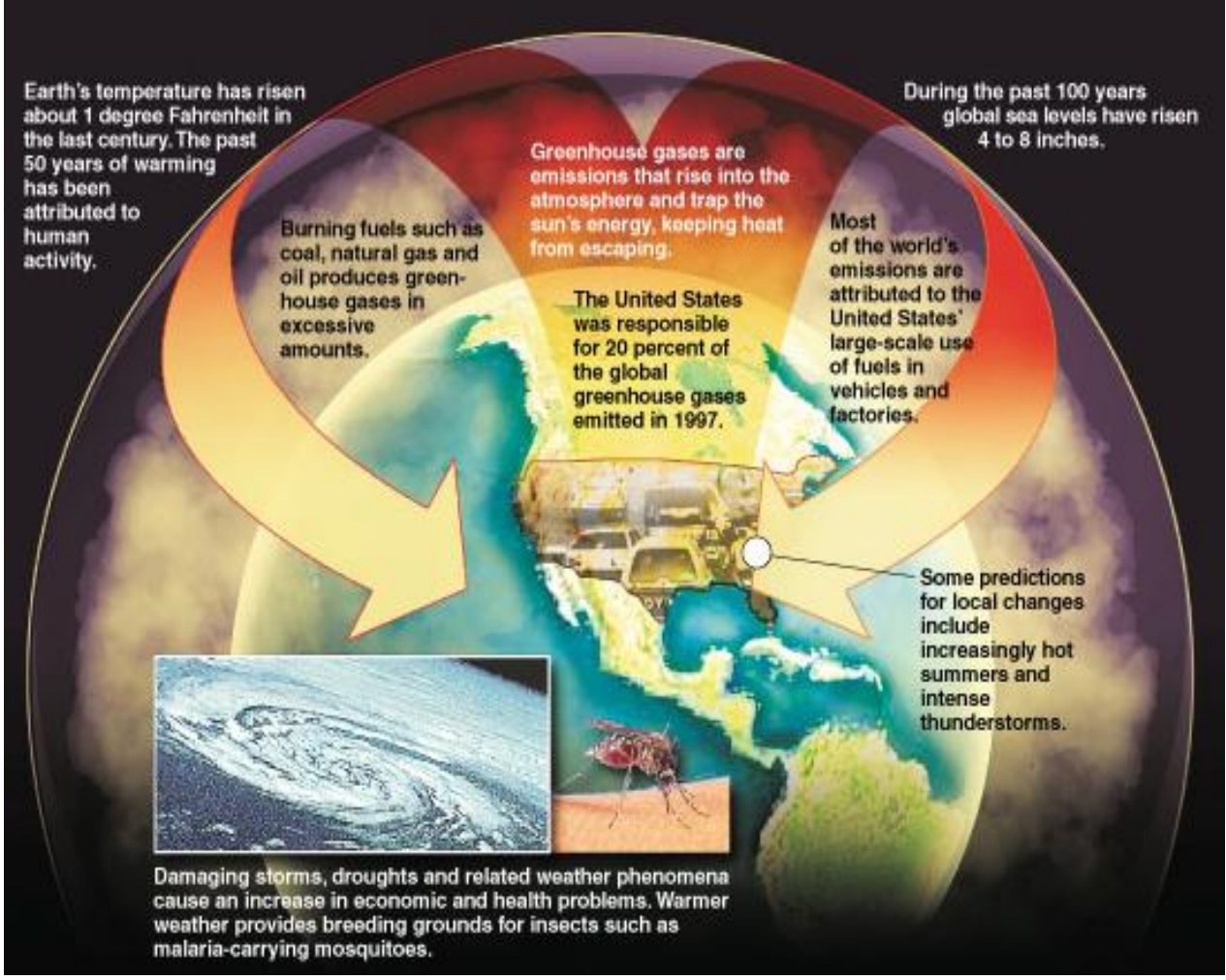

Image 5: Global Warming Causes and Effects ${ }^{[81]}$

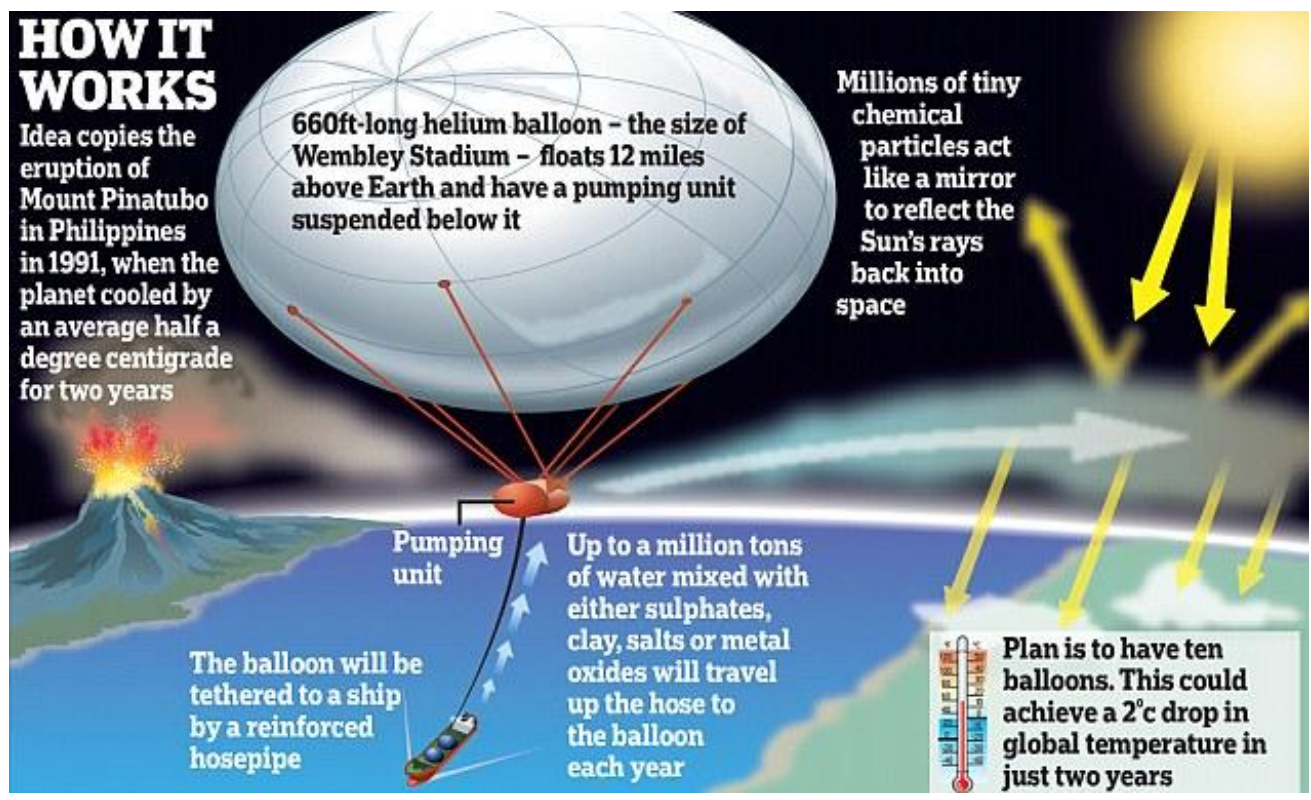

Image 6: Environment Balloon that Scientists Hope Could Stop Global Warming ${ }^{[82]}$ 


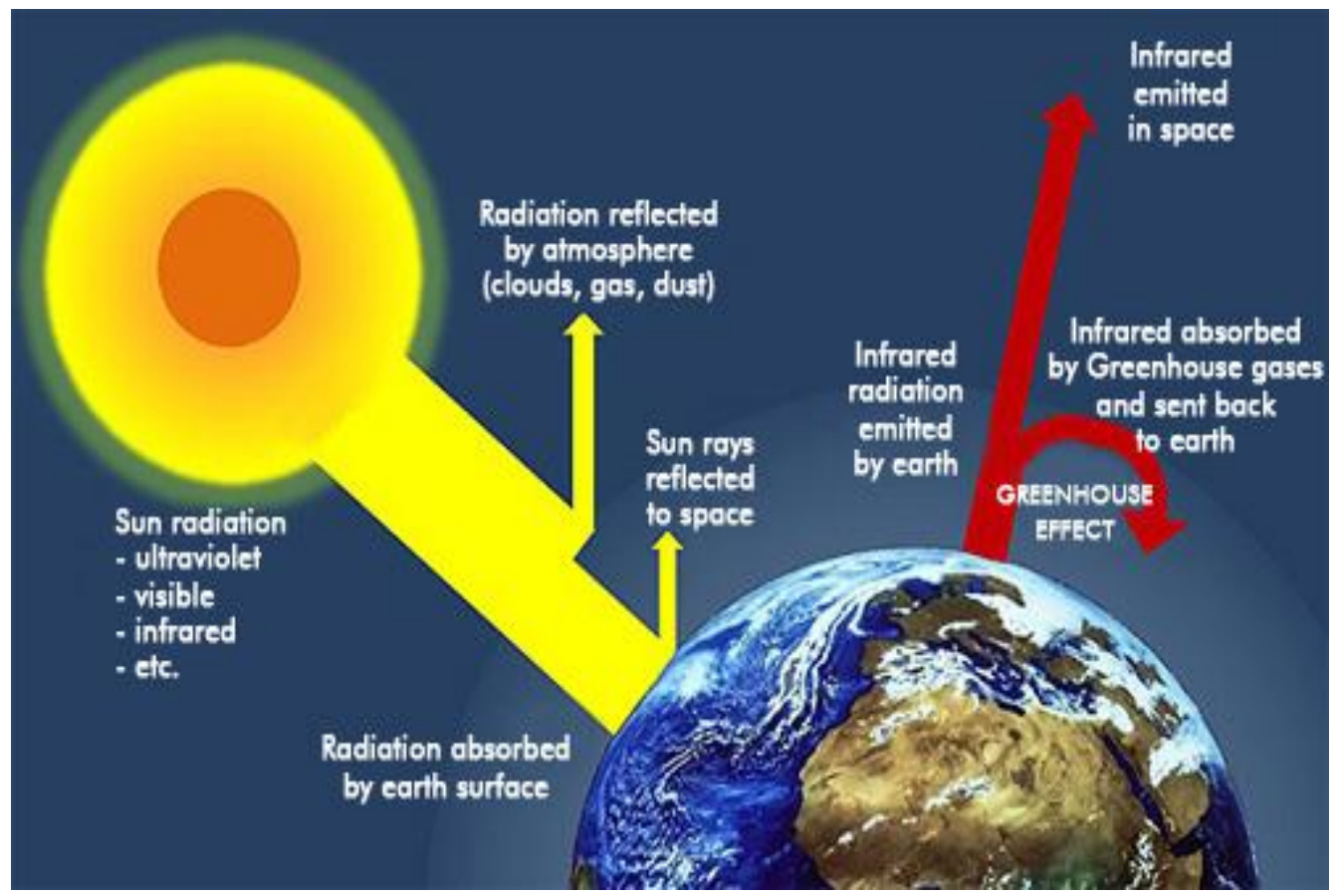

Image 7: Greenhouse Effects ${ }^{[83]}$

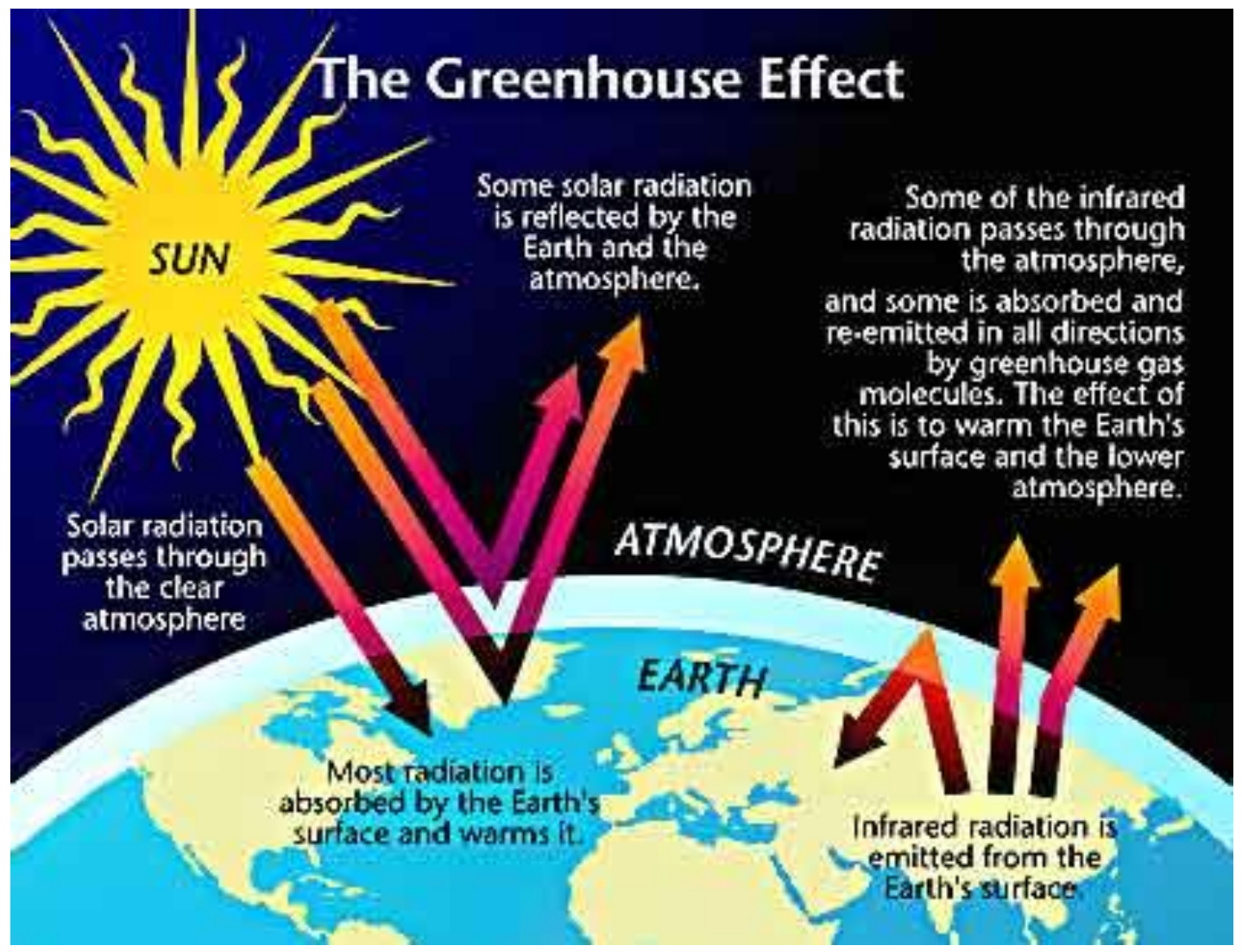

Image 8: Greenhouse Effect ${ }^{[84]}$ 


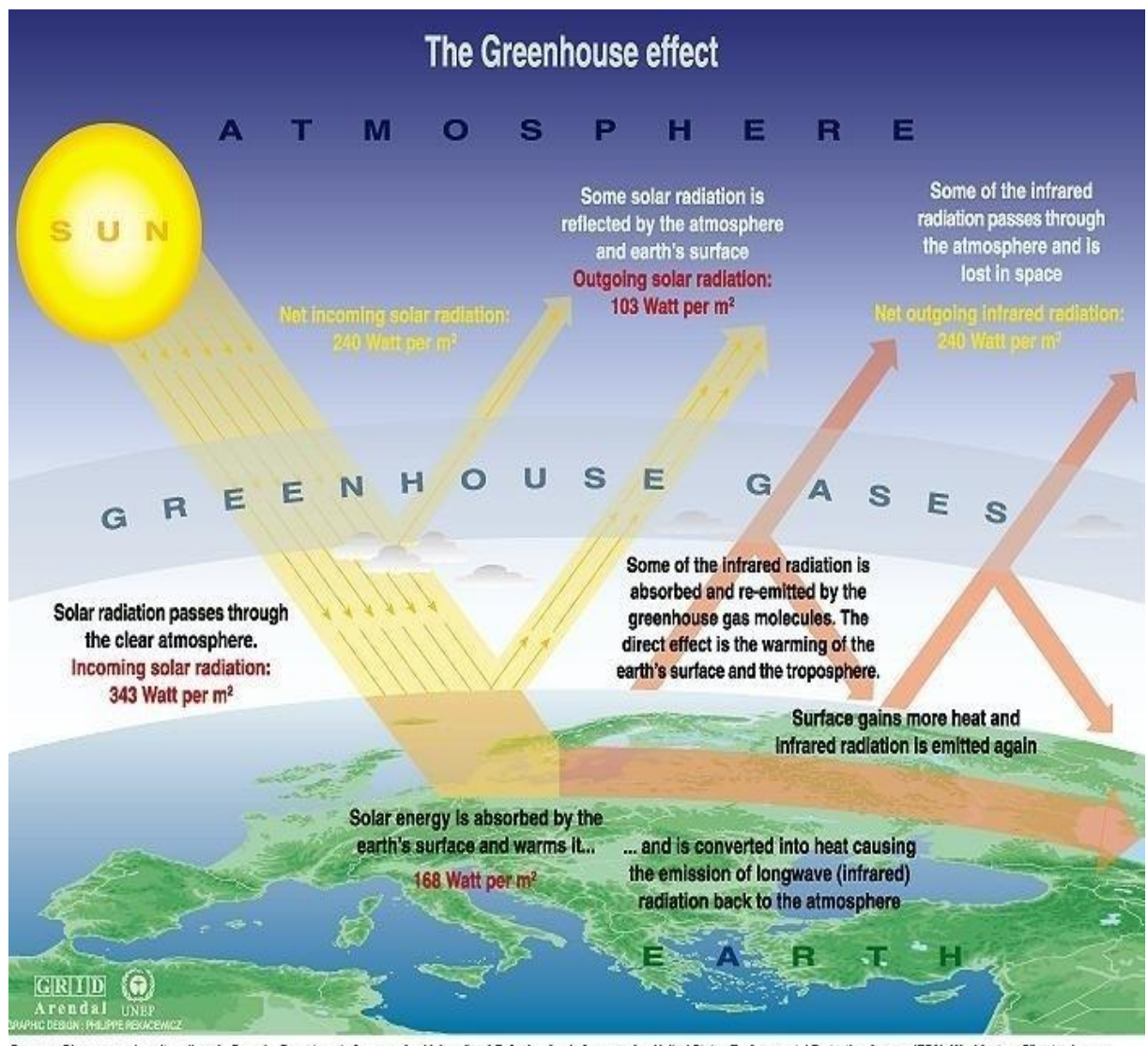

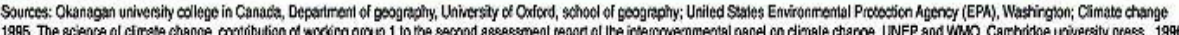

Image 9: Climate Change and Green Facts-global Challenges ${ }^{[85]}$

Sources: Okanagan university college of Canada, department of Geography, University of Oxford, School of Geography, United States Environmental Protection Agency (EPA). Washington; Climate change working group 1 to the second assessment report of the intergovernmental panel on climate change, UNEP and WMO, Cambridge University Press, 1996

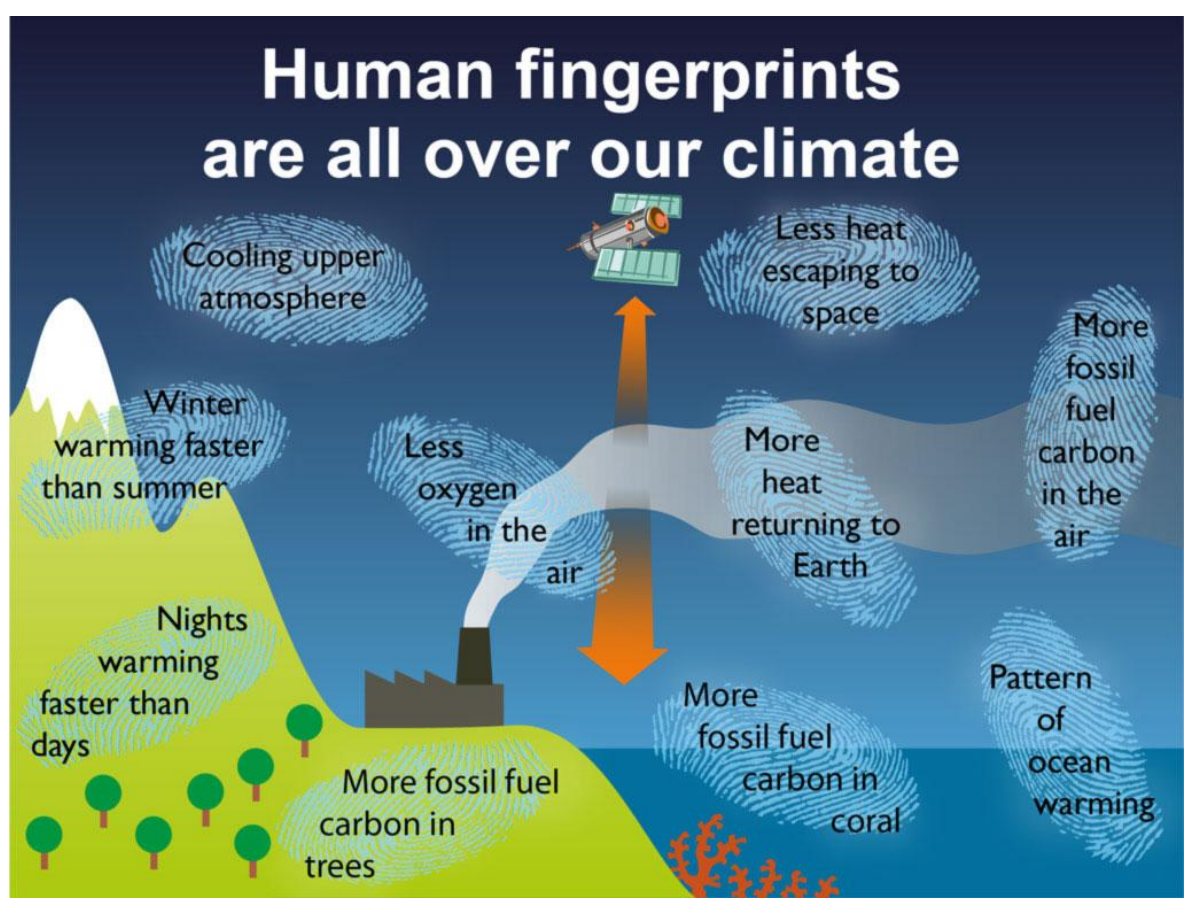

Image10: Human Fingerprints over the Climate ${ }^{[86]}$ 


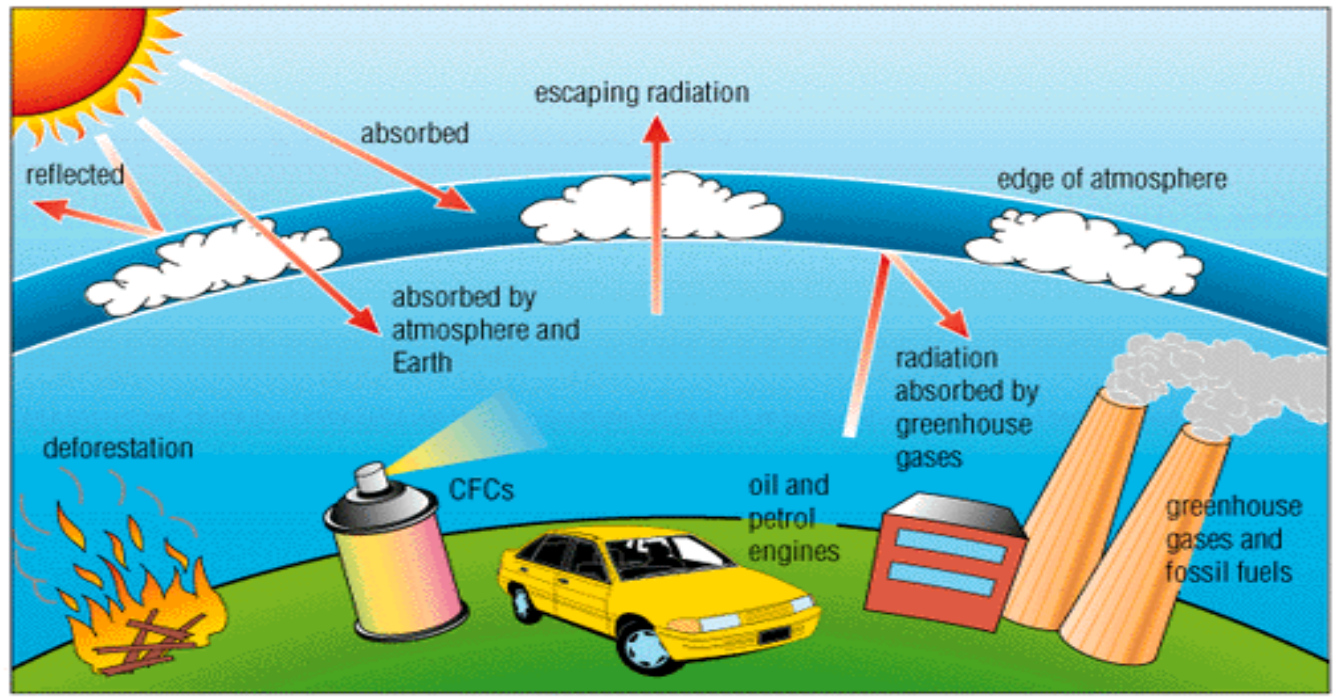

Image 11: Greenhouse Effect ${ }^{[87]}$

\section{Indicators of a Human Fingerprint on Climate Change}

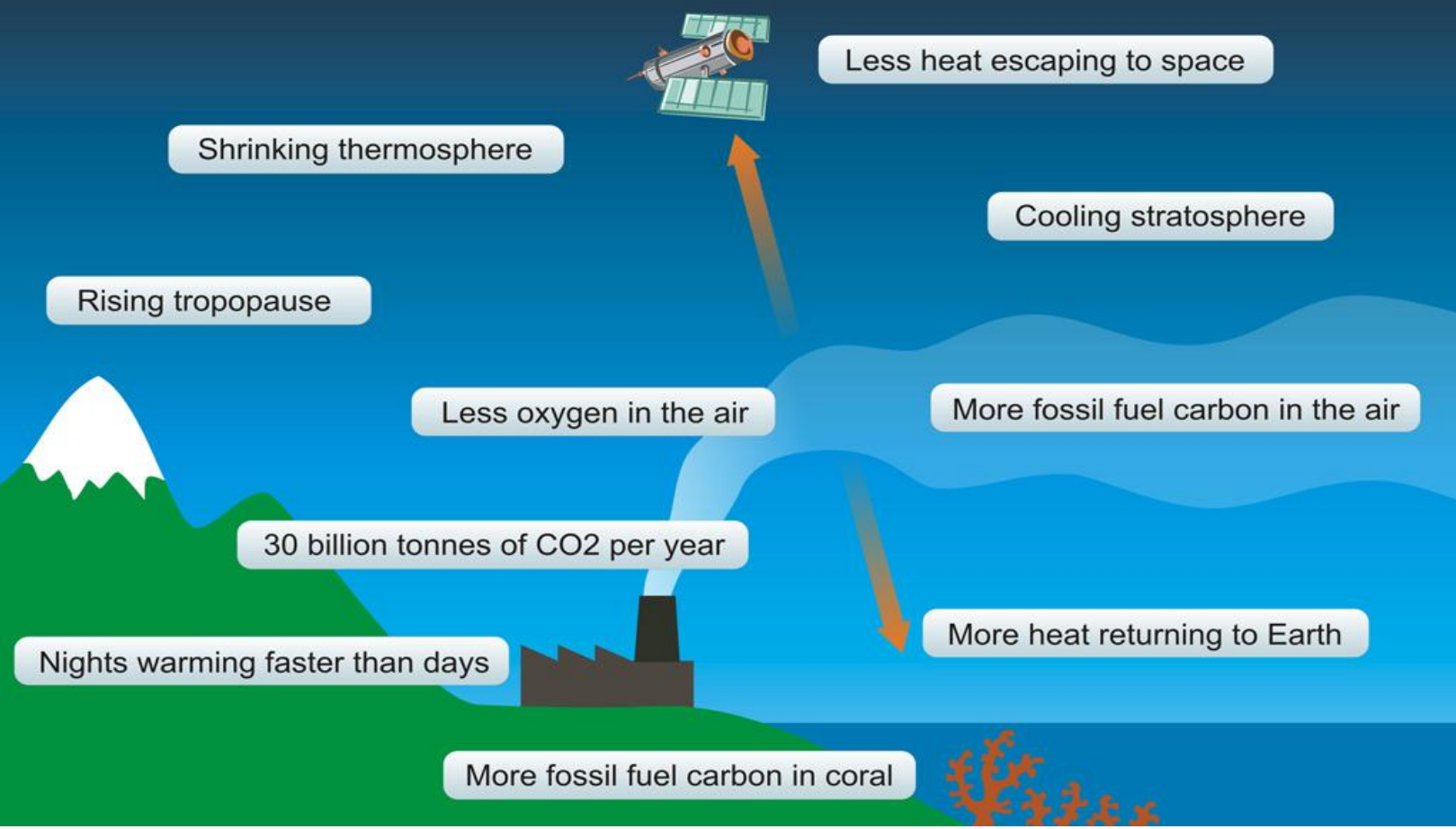

Image 12: The World of Energy ${ }^{[88]}$

Warming happening more quickly than predicted 


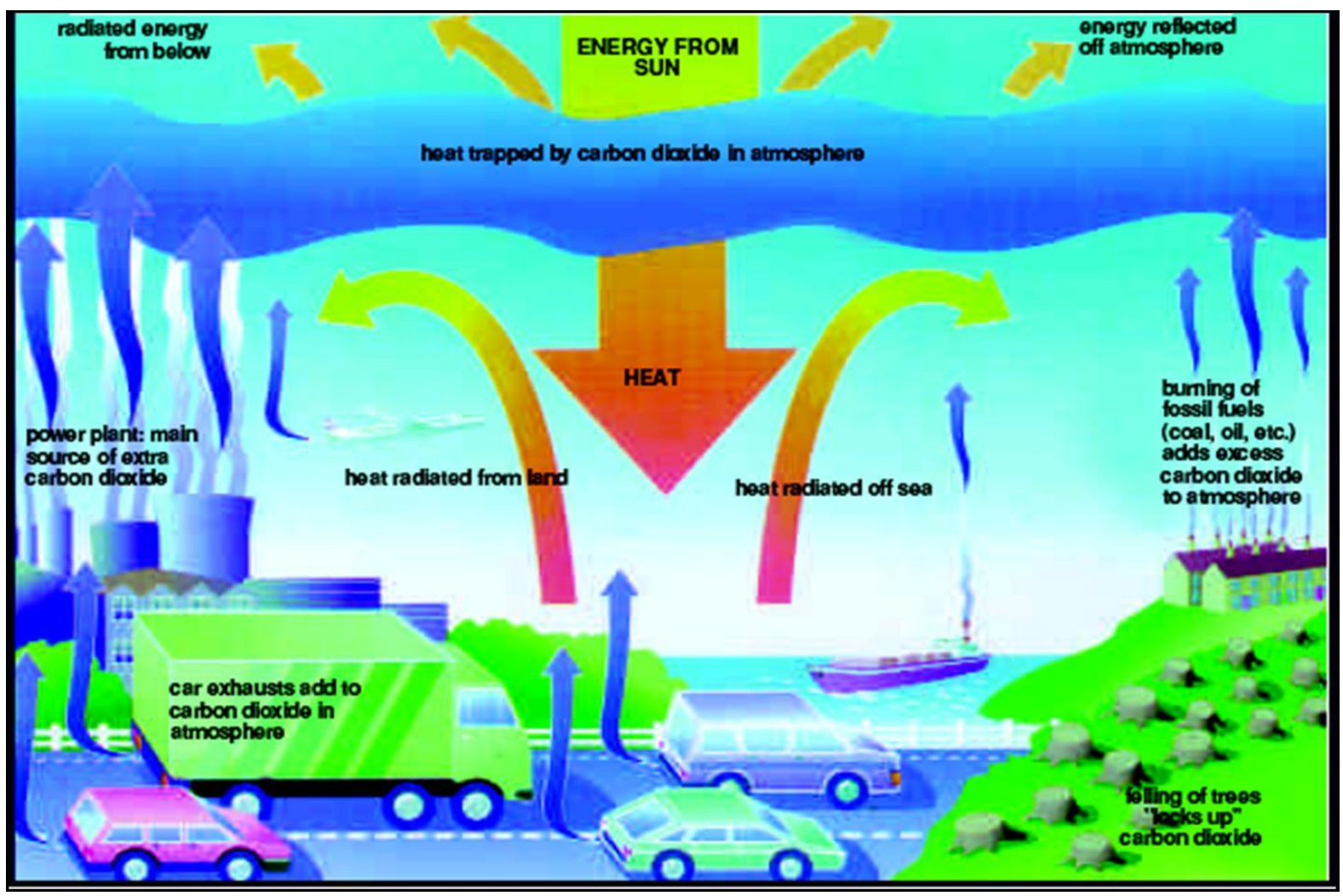

Image 13: Green House Effect

\section{Impacts of Global Warming}

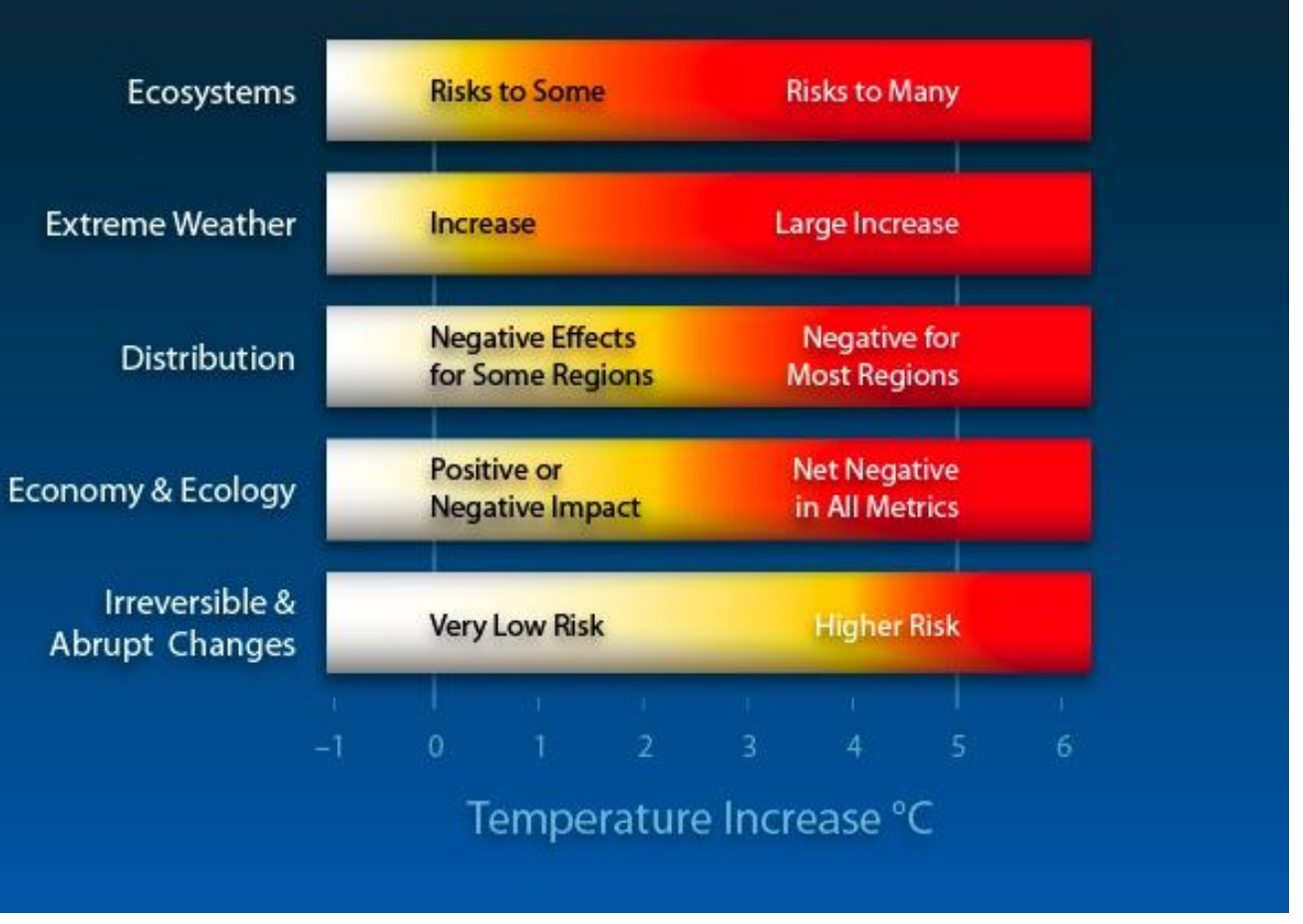

Image 14: Impacts of Global Warming ${ }^{[90]}$ 


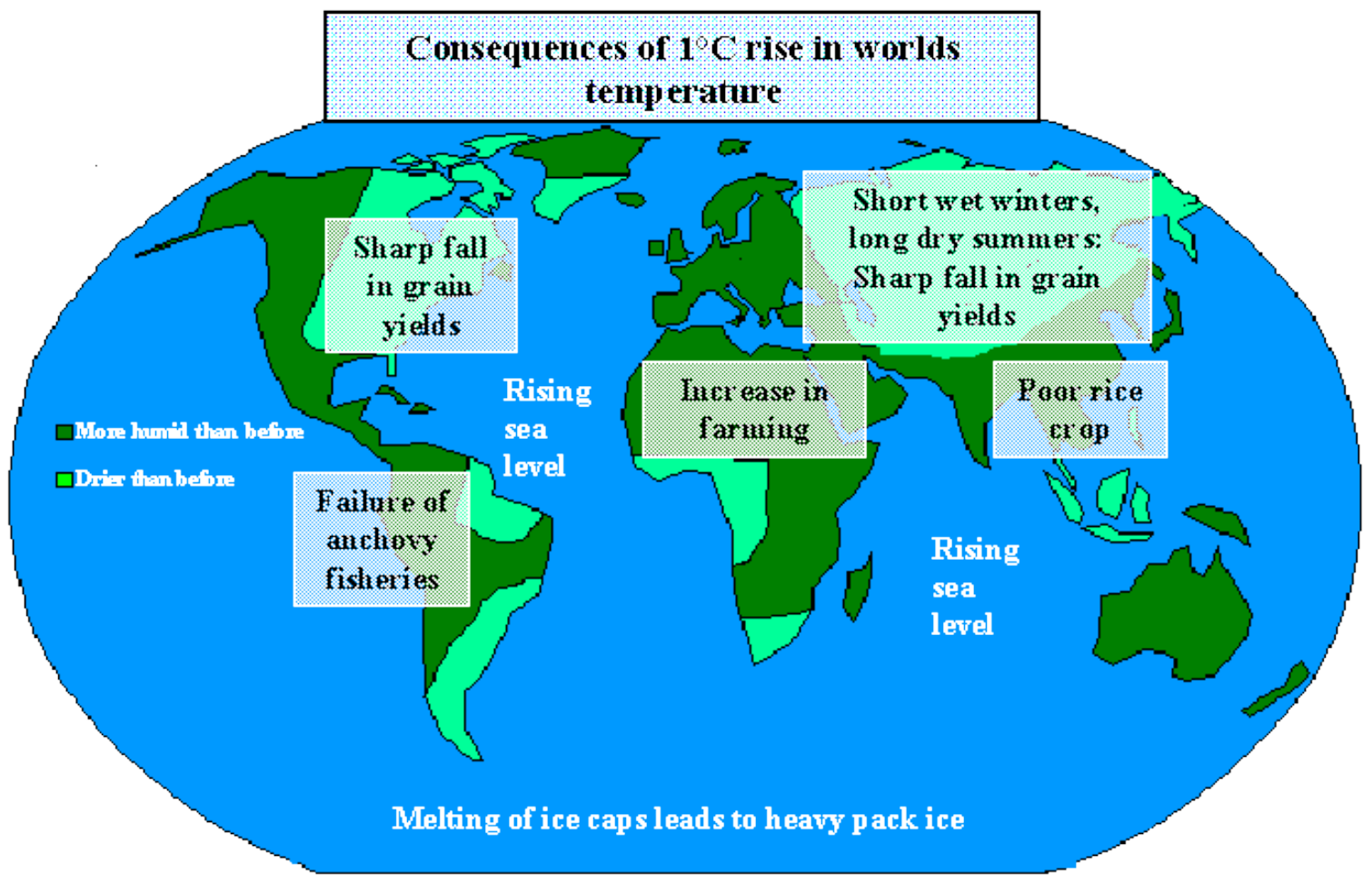

Image 15: Effect of Climate Change and Global Warming on Agriculture ${ }^{\text {[91] }}$

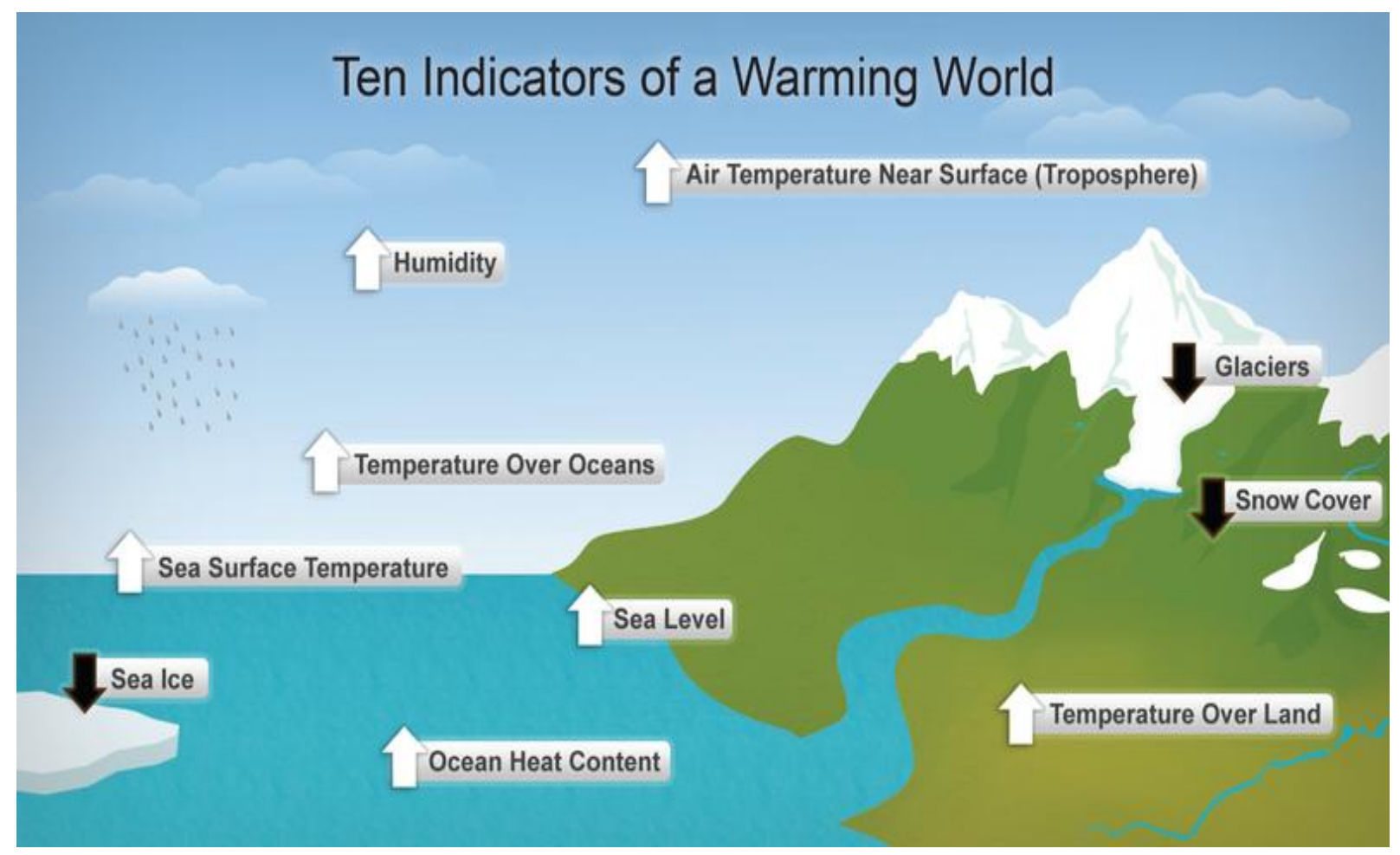

Image 16: Warming Happening More Quickly than Predicted ${ }^{[2]}$ 


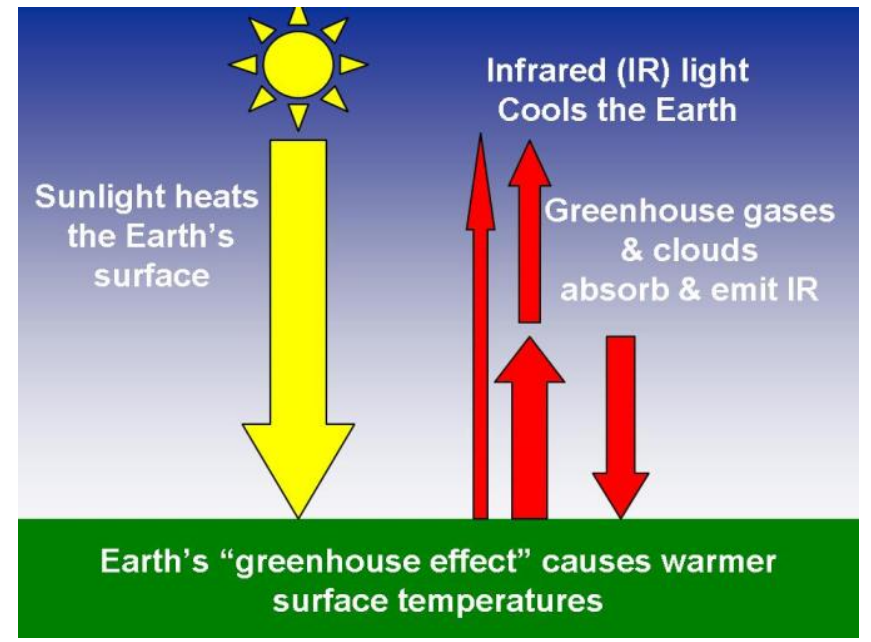

Image 17: Simplified Greenhouse effect Greenhouse Effect ${ }^{[33]}$

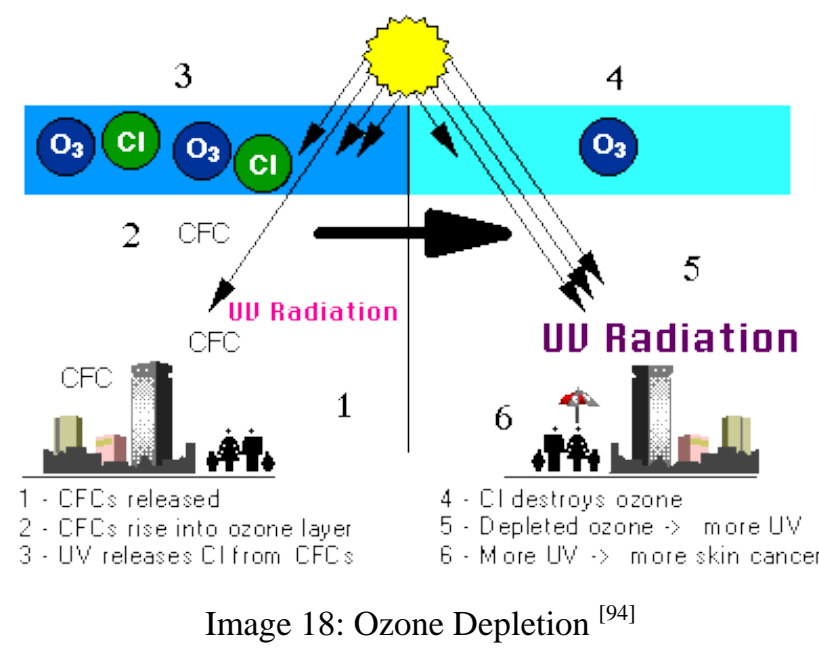

Ozone depletion: When CFCs and HCFCs reach the stratosphere, the ultraviolet radiation from the sun causes them to break apart and release chlorine atoms which react with ozone, starting chemical cycles of ozone destruction that deplete the ozone layer. One chlorine atom can break apart more than 100,000 ozone molecules.

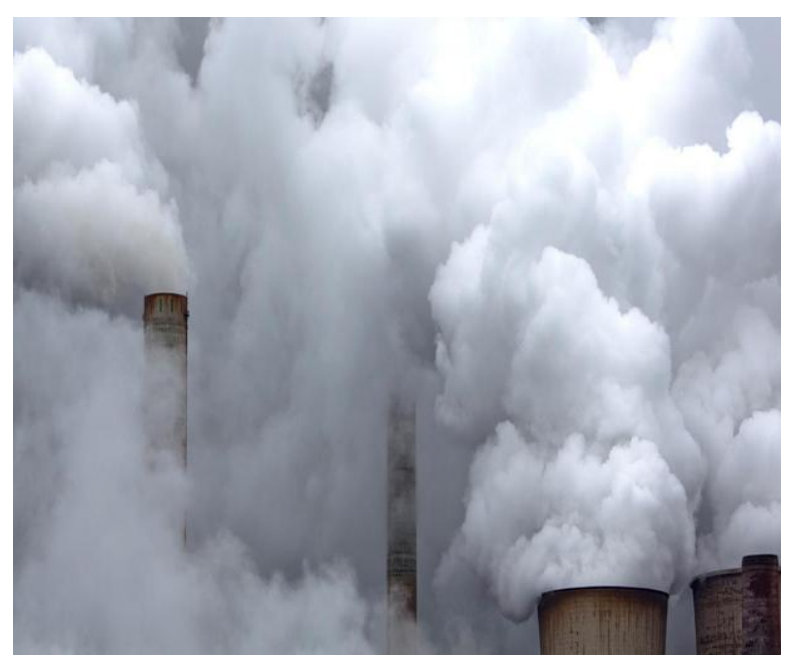

Global warming solutions: Reduce emissions

Image 19: Energy-coal-power-plant-billowing-smokestacks-and-cooling-tower ${ }^{\text {[95] }}$ 


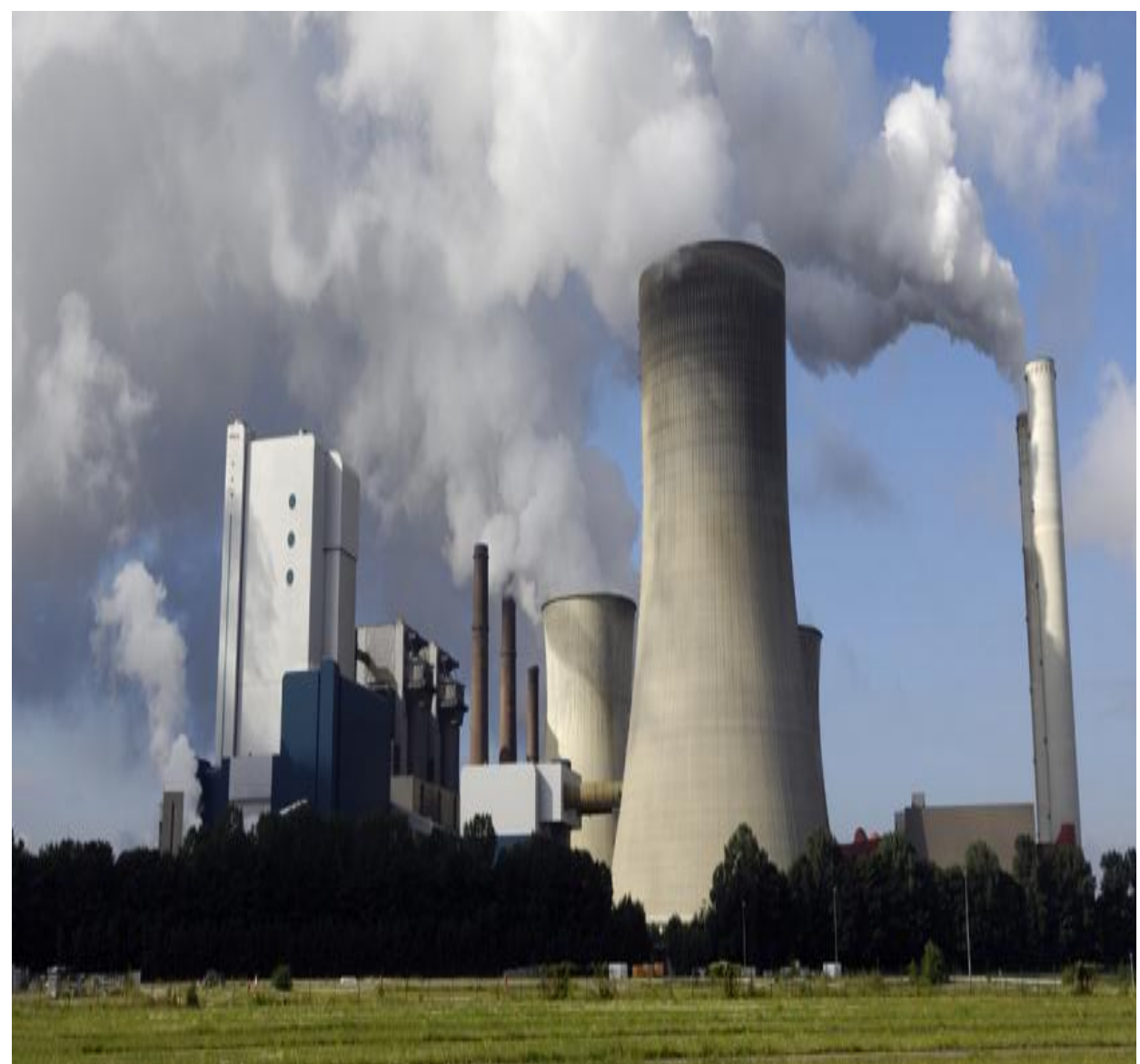

The clean power plan: a climate game changer

Image 20: Energy-coal-power-plant-with-smokestacks-and-cooling-towers ${ }^{[96]}$

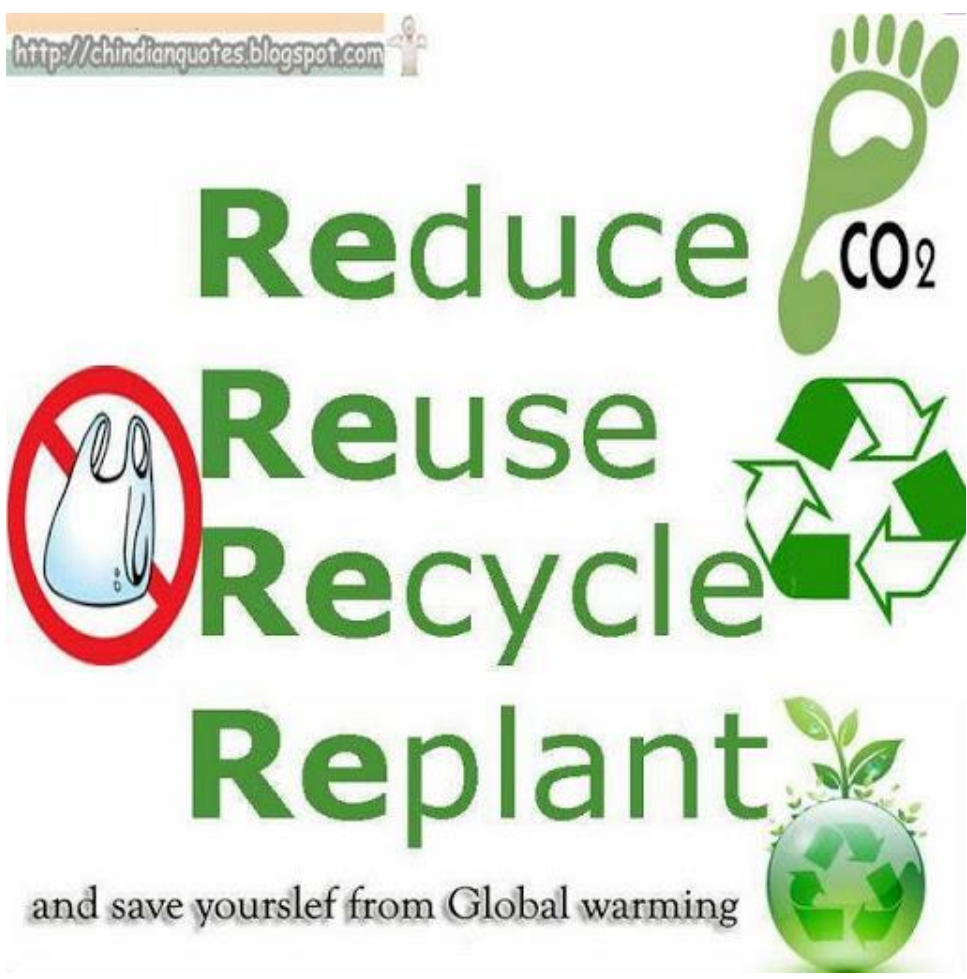

Image 21: Reduce Carbon Foot Prints and Overuse/Misuse of Resources, Reuse and Recycle Resources and Replant the Trees to save yourself from Global Warming. [97] 


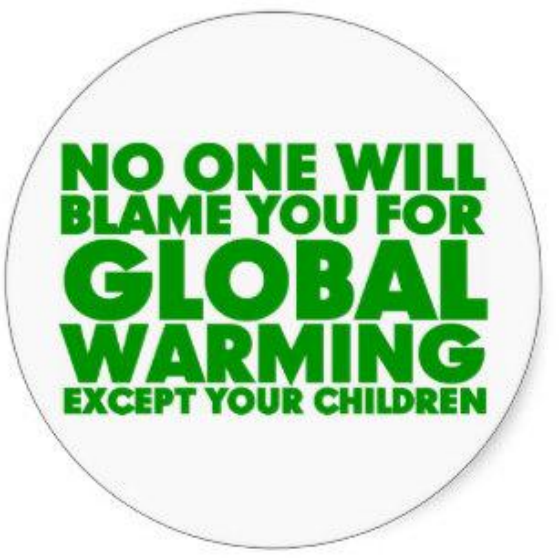

Image 22: A Slogan against Global Warming [98]

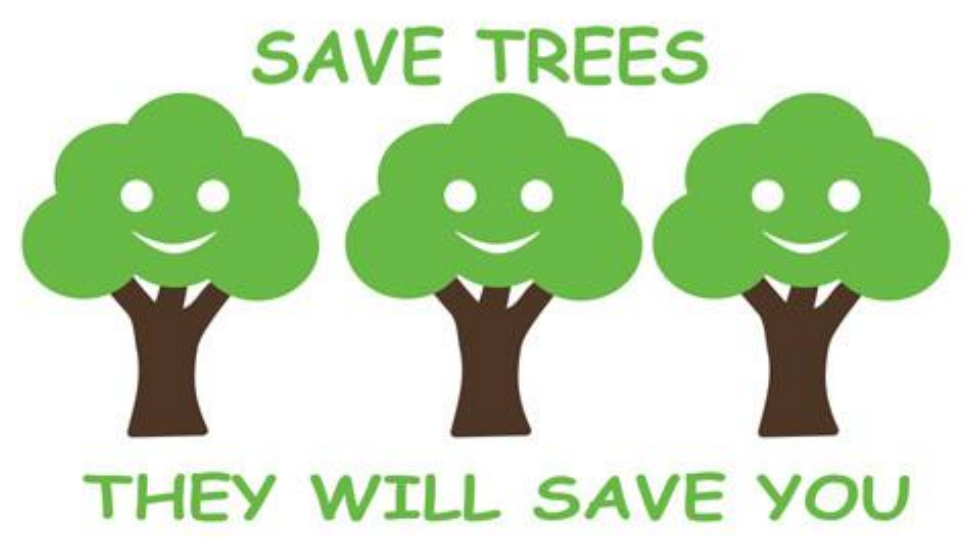

Image 23: Saving the Green Trees ${ }^{[99]}$

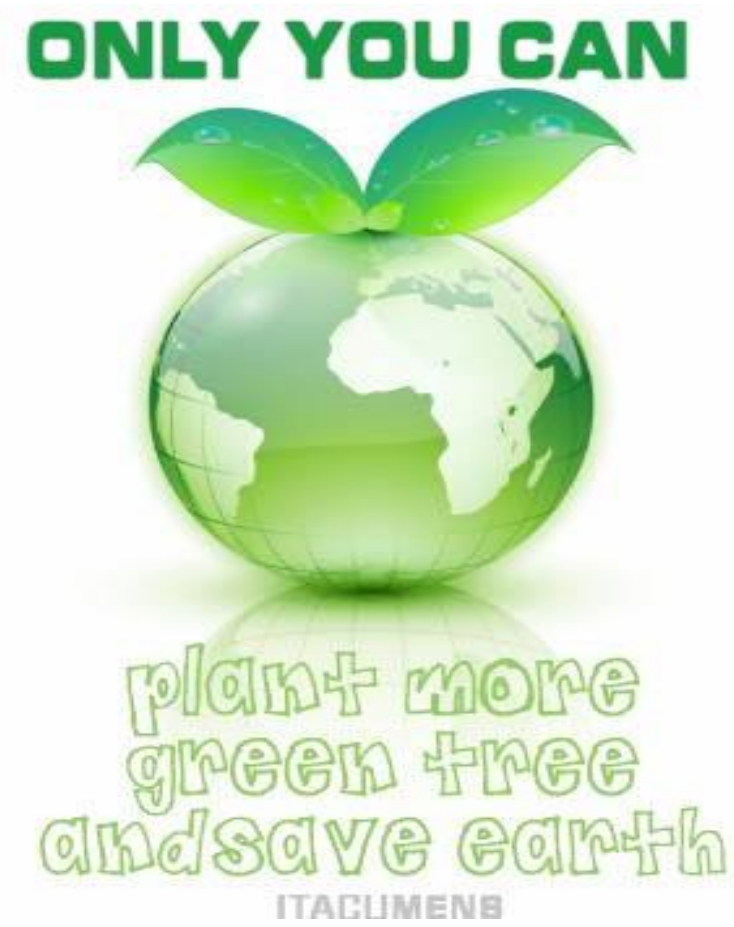

Image 24: Plant more and more Trees as they Play a Major Role in Stopping this Threat of Global Warming. ${ }^{[100]}$ 


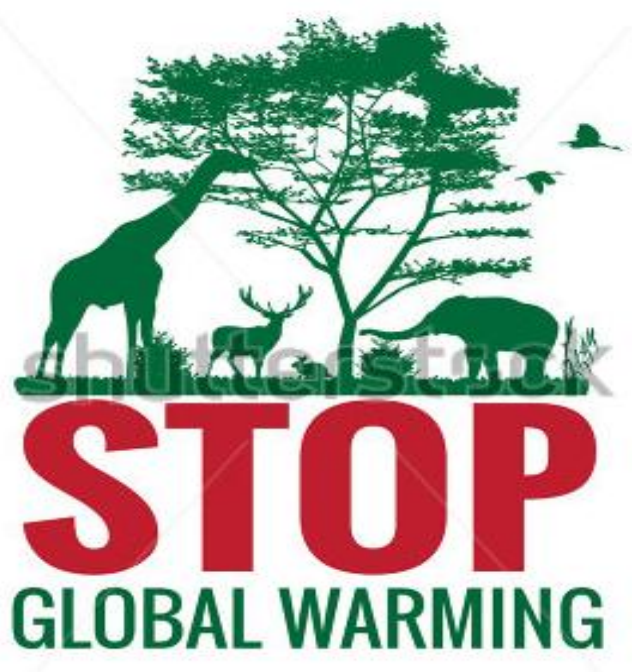

Image 25: Stop Global Warming ${ }^{\text {[101] }}$ 